\title{
Human Health Risk Regulation of Reproductive Toxicity, Neurotoxicity, and Endocrine Disruption in Special Populations Exposed to Organophosphorus Flame Retardants
}

\author{
Jiawen Yang \\ North China Electric Power University - Beijing Campus: North China Electric Power University \\ Wenjin Zhao \\ Jilin University \\ Yu Li ( $D$ liyuxx8@hotmail.com ) \\ North China Electric Power University - Beijing Campus: North China Electric Power University
}

\section{Research Article}

Keywords: organophosphorus flame retardants (OPFRs), pregnant women, complementary food scheme (CFS), competitive binding, human health risk regulation

Posted Date: March 6th, 2021

DOI: https://doi.org/10.21203/rs.3.rs-270820/v1

License: (c) (i) This work is licensed under a Creative Commons Attribution 4.0 International License.

Read Full License 
1 Human health risk regulation of reproductive toxicity, neurotoxicity,

\title{
and endocrine disruption in special populations exposed to
}

\section{organophosphorus flame retardants}

\author{
Jiawen Yang ${ }^{\text {a }}$, Wenjin Zhao ${ }^{\text {b }}$, Yu Li ${ }^{a^{*}}$
}

${ }^{a}$ MOE Key Laboratory of Resources and Environmental Systems Optimization, North China Electric Power University, Beijing 102206, China

${ }^{\mathrm{b}}$ College of New Energy and Environment, Jilin University, Changchun 130012,

China

\section{* Corresponding author:}

Yu Li: liyuxx8@hotmail.com

The e-mail addresses of all authors:

Jiawen Yang: yangjiawen236@163.com;

Wenjin Zhao: zhaowj@jlu.edu.cn

Abstract: In this study, the joint toxicological characteristics of reproductive toxicity, neurotoxicity, and endocrine disruption (ED) by organophosphorus flame retardants (OPFRs) were regulated by process control. Molecular docking technology, molecular dynamics (MD), 2D-QSAR model, and density functional theory (DFT) were used to develop a health risk regulation scheme for special population such as pregnant women exposed to OPFRs. It was found that MD simulations confirmed the effectiveness of the recommended complementary food scheme (CFS) for the pregnant women with low health risk. When $\beta$-lactoglobulin, $\alpha$-lactoalbumin, milk fat globule membrane (MFGM) protein, ovalbumin (OVA), ovotransferrin (OVT), vitamin, plant pigment, apple polyphenols, and malic acid were present in the CFS, the joint toxicity of OPFRs in pregnant women were significantly decreased by 
$91.18 \%$. The reproductive toxicity played a dominant role in the joint toxicity and could be reduced by $82.48 \%$ under the recommended CFS. There was a competitive relationship between the nutrients in the recommended CFS and OPFRs binding to the joint toxic receptor (JTR). The former could easily occupy the target binding spot of the JTR protein, which reduced or prevented the binding of OPFRs to the JTR. In addition, simulation of OPFRs molecular metabolic pathways in pregnant women under the recommended CFS showed that the binding affinity between OPFRs and six metabolic kinases in pregnant women was significantly decreased $(-28.85 \%-$ 87.54\%), indicating that the inhibition effect of OPFRs on normal biochemical reactions in the human body was significantly reduced, which to a certain extent verified the effectiveness of the recommended CFS.

Keywords: organophosphorus flame retardants (OPFRs), pregnant women, complementary food scheme (CFS), competitive binding, human health risk regulation

\section{Declarations}

Funding This research did not receive any specific grant from funding agencies in the public, commercial, or not-for-profit sectors.

Conflict of interest The authors declare that they have no conflict of interest.

Availability of data and material All supporting data are included within the main article and supplementary files.

Code availability Not applicable.

Authors' contributions Conceptualization: Jiawen Yang, Yu Li; Methodology: Jiawen Yang, Wenjin Zhao; data curation: Jiawen Yang, Wenjin Zhao; Formal analysis and investigation: Jiawen Yang; Writing - original draft preparation: Jiawen 
51 Yang; Writing - review and editing: Jiawen Yang, Yu Li; Resources: Jiawen Yang,

52 Yu Li; Supervision: Yu Li. All authors have read and agreed to the published version

53 of the manuscript.

54 Ethics approval Not applicable.

55 Consent to Participate Informed consent was obtained from all individual 56 participants included in the study.

57 Consent for Publication The authors affirm that human research participants 58 provided informed consent for publication of the aggregate data produced in the study.

\section{Appendix A. Supplementary data}

60 Calculated values of spectral parameters, geometric parameters, electronic 61 parameters and physicochemical parameters of OPFR molecules before molecular 62 modification (Table S1); the 32 orthogonal experimental groups of CFS generated by 63 Taguchi experiment design (Table S2) and the force field diagram of OPFRs docked 64 with JTR (Figure S1) can be found in the online version. 


\section{Introduction}

Brominated flame retardants (BFRs) such as polybrominated diphenyl ethers (PBDEs), polychlorinated biphenyls (PCBs), hexabromocyclododecane (HBCD), tetrabromobisphenol A, and DBDPE have been listed as persistent organic pollutants (POPs) by the Stockholm Convention, and their use has been restricted or even banned. Organophosphorus flame retardants (OPFRs) are widely used as substitutes for BFRs for various home and office applications (Tavoloni et al. 2020; Mao et al. 2020; Chen et al. 2019; Yu et al. 2019). OPFRs are mainly found in building materials, such as rigid polyurethane foam for insulation, construction, and refrigeration (Yang et al. 2017), flexible polyurethane foams, plastics, clothing, and textiles for interior upholstery such as furniture and mattresses (Zhou et al. 2019; Ospina et al. 2018), electronic products and a few baby products (Wang et al. 2020; Wiersielis et al. 2020). Triphenyl phosphate (TPHP), tris(1,3-dichloro-2-propyl) phosphate (TDCPP), and tris(2-chloroethyl) phosphate (TCEP) can be frequently detected in pregnant women's homes (Percy et al. 2020; Wiersielis et al. 2020; Chen et al. 2015; Zhang et al. 2016). OPFRs are often used in household furniture and baby products; thus, pregnant women and their babies are inevitably exposed to them (Hoffman et al. 2014; Thomas et al. 2017).

As a substitute for POPs such as PDBEs, in terms of harmful effects, OPFRs are not completely separated from POPs. OPFRs still have a variety of biological toxicities, including developmental neurotoxicity, which is associated with adverse reproductive/developmental nervous system effects in animals and humans (Sun et al. 2016; Baldwin et al. 2017; Gu et al. 2018). It was found that the lethal concentration $50 \%\left(\mathrm{LC}_{50}\right)$ and concentration for $50 \%$ of maximal effect $\left(\mathrm{EC}_{50}\right)$ values of OPFRs were similar to the toxicity values of BFRs such as PBDEs, even one or two orders of 
magnitude less than the $\mathrm{LC}_{50}$ and $\mathrm{EC}_{50}$ values of the various flame retardants such as OPFRs, PBDEs, PCBs, HBCD, tetrabromobisphenol A, and DBDPE (Gu et al. 2018; Chu et al. 2019). As the values of $\mathrm{LC}_{50}$ and $\mathrm{EC}_{50}$ decreases, the toxicity increases. Therefore, the toxic effect of OPFRs cannot be ignored. TDCPP and TCIPP have been known as carcinogenic and were removed from children's pajamas in the late 1970s, but in recent decades, the production of OPFRs as a flame retardant for other applications has increased significantly (Percy et al. 2020). TCEP and TPHP are neurotoxic to some animals (Gu et al. 2018; Wang et al. 2015). Besides, TPHP had been used as a phthalate substitute in some personal care products (e.g., nail polish), providing another potential exposure route of OPFRs hazards to the environment and human health (Young et al. 2018).

As additive flame retardants, OPFRs exist in products through physical combination. During the manufacturing, processing, and use of products, OPFRs easily enter into the environment and human food chain through leaching, deposition, inhalation, ingestion, and dermal absorption and accumulate in human milk and urine (Wei et al. 2015; Zhang et al. 2016; Ospina et al. 2018; Schreder et al. 2016). Handto-mouth contact of the human body (dust inhalation and skin absorption) to OPFRs is one of the most common OPFR absorption pathways for people living in indoor environments (Hou et al. 2016). Dietary intake is also an important way for the human body to absorb OPFRs. The widespread existence of OPFRs indoors implies that pregnant women are potentially exposed to them, and thus the risk of OPFRs molecular toxicity to pregnant women has aroused widespread concern in late years. Recent studies have shown that TDCPP, TCP, and TPP with a median concentration of about $1-6 \mu \mathrm{g} / \mathrm{g}$ household dust were inadvertently inhaled by pregnant women or growing infants (Fan et al. 2014; Meeker et al. 2013; Carignan et al. 2013). TDCPP, 
TCP, and TPP can be detected in urine, breast milk, and blood samples of pregnant women at concentrations ranging from $1-100 \mathrm{ng} / \mathrm{mL}$ or $1-100 \mathrm{ng} / \mathrm{g}$ lipids. Metabolites of OPFRs were detected in pregnant women during the perinatal period (Hoffman et al. 2015), which were associated with an increased risk of high body mass index (BMI) and adverse neurological outcomes in children (Boyle et al. 2019; Doherty et al. 2019). Bis(1, 3-dichloroisopropyl) phosphate (BDCIPP), the metabolite of tris(1,3-dichloro-2-propyl) phosphate (TDCPP), was detected in the urine samples of the children across the entire United States at a median concentration of $\sim 2.8$ $\mathrm{ng} / \mathrm{mL}$ (Butt et al. 2016). BDCIPP was detected in all the urine samples of the Australian children, with a median concentration of $7.8 \mu \mathrm{g} / \mathrm{g}$ (He et al. 2018). The presence of OPFRs metabolites such as diphenyl phosphate (DPHP), bis(1,3-dichloro2-propyl) phosphate (BDCIPP), and bis(2-chloroethyl) phosphate (BCEP) in the urine samples of the pregnant women $(n=357)$ at 16 and 26 weeks of gestation and at birth confirmed that the pregnant women were indeed exposed to OPFRs during fetal development (Percy et al.. 2020). This raised a major concern in the scientific community about the continuous OPFRs exposure and their associated health risks to pregnant women. Given this, Zhang et al. (2016) compared the dietary intake (EDI) of OPFRs with their daily reference dose (RfD) (ng/kg bw/day). It was found that the estimated exposure levels of most of the compounds were at least two orders of magnitude lower than their RfD values. The human health risk assessment for selected OPFRs was probably underestimated because other possible OPFRs already present in the food were not included. Thus, it is necessary to reduce the human health risks of OPFRs in special populations.

Pregnancy is a critical period for the formation and development of fetal tissues and organs and is potentially vulnerable to environmental toxins for pregnant women 
and their fetuses. Past studies have shown that mammals are particularly sensitive to organic flame retardants (such as reproductive neurotoxicants and endocrine disruptors) during uterine and neonatal development (Schneider et al. 2014). OPFRs in pregnant women affect the hormone secretion sensitivity, lead to reproductive and immune dysfunction, and affect the reproductive process. OPFRs also have adverse effects on the long-term physical development and neurocognitive development of the fetus (Percy et al. 2020; Gu et al. 2018). Therefore, dietary interventions during pregnancy are very important to ensure the health of the pregnant women and fetus, reduce the human health risks of OPFRs molecular reproductive toxicity, neurotoxicity, and endocrine disruption (ED), and minimize the occurrence of adverse pregnancy outcomes (Adams et al. 2020). Hence, to reduce the OPFRs molecular joint toxicity risk in pregnant women, it is recommended to formulate a recommended complementary food scheme (CFS) for pregnant women to create in vivo obstruction in the binding process of OPFRs and joint toxicity receptor (JTR) protein. In this study, molecular docking and 2D-QSAR model were used to screen the molecular parameters that significantly affected the joint toxicity of OPFRs and to reveal the joint toxicity mechanism of OPFRs in pregnant women firstly. Secondly, MD methods based on the Taguchi experiment design were used to develop recommended CFS that significantly improved the human health risks in pregnant women exposed to OPFRs. Finally, MD and DFT methods were used to quantify the weight of neurotoxicity, reproductive toxicity, and ED toxicity of OPFRs in pregnant women. To the best of our knowledge, no study on the CFS to improve or reduce human health risks of OPFRs in pregnant women has been reported in the literature.

\section{Material and methods}

2.1 Comprehensive evaluation method for OPFRs molecular joint toxicity-- 


\section{Molecular docking and MD method}

The receptor proteins of the human neurotoxicity (glucocorticoid receptor, GR) (Chen et al. 2015; Frank et al. 2018), reproductive toxicity (peroxisome proliferatoractivated receptor, PPAR) (Kojima et al. 2013; Kuwabara et al. 2012), and ED toxicity (estrogen receptor, ER) (Souza et al. 2017) were obtained from Protein Data Bank (PDB, http://www.rcsb.org/pdb) and their PDB IDs were 6CFN, 3VI8, and 5TOA, respectively. ZDOCK module in Discovery Studio 4.0 (DS, Accelrys, Inc., San Diego, American) software was used to dock 20 OPFRs molecules with three toxic receptor protein docking complexes in turn. The binding free energy $\left(\triangle \mathrm{G}_{\text {bind }}\right.$ ) characterized the joint toxicity of OPFRs reproductive toxicity, neurotoxicity, and ED toxicity in special populations. MD method was used to calculate the $\triangle \mathrm{G}_{\text {bind }}$ of 20 OPFRs molecules and the complex of JTR protein. The calculation was mainly based on the MD simulation module of Gromacs software in the Dell PowerEdge R7425 server. The complex of OPFR molecules and JTR protein was placed in a cube with a side length of $8.3 \mathrm{~nm}$. The GROMOS96 $43 \mathrm{~A} 1$ force field was used for molecular constraint, and $\mathrm{Na}^{+}$was added to neutralize the system charge. The above composite system was set as a group, and the energy minimization simulations based on the steepest gradient method were performed with the simulated steps set to 100,000 . The heat bath and pressure simulation time of the composite system was set to 100 ps with a constant standard atmospheric pressure of 1 bar and the dynamic simulation calculation time of each level was equal to $200 \mathrm{ps}$. It was reported that as the $\triangle \mathrm{G}_{\text {bind }}$ value of the OPFRs molecules and the JTR proteins complex decreased, the binding affinity of the complex was increased (Yang et al. 2020a). The calculated values of $\triangle \mathrm{G}_{\text {bind }}$ of OPFRs molecule and JTR protein complex are shown in Table S1. The absolute value of $\triangle G_{\text {bind }}$ was used to characterize the joint toxicity of OPFRs 
molecules in the special population. With the increase in the absolute value of $\triangle G_{\text {bind }}$, the joint effects of reproductive toxicity, neurotoxicity, and ED toxicity of OPFRs were increased.

\subsection{Analysis of the joint toxicity mechanism of OPFRs molecules by 2D-QASR} model assisted by density functional theory (DFT)

We used Gaussian 09 to optimize the structures based on the ground state of DFT at B3LYP level and 6-311 G (d,p) basic set and Chemdraw12.0 software to calculate the seven geometrical parameters, five electronic parameters, eight physicochemical parameters, and seven spectral parameters of the OPFRs molecules. The calculated parameters of 20 OPFRs molecules are shown in Table S1 (Chen et al. 2020; Shi et al. 2015). These parameters were selected as the independent variables, while the joint toxic evaluation value of reproductive toxicity, neurotoxicity, and ED toxicity (the $\triangle \mathrm{G}_{\text {bind }}$ of complex of OPFRs molecules and JTP protein) were the dependent variables (Du et al. 2019; Li et al. 2020). Based on these data, we screened out molecular descriptors using the stepwise regression method in SPSS Statistics 2.0 software. A 2D-QASR model of OPFRs molecular reproductive toxicity, neurotoxicity, and ED toxicity was constructed with $15(\geq 5)$ molecules (out of 20 molecules) as the training set and five molecules $(\geq 5)$ as the test set (Golbraikh et al. 2002). The sensitivity analysis method was used to analyze the parameters that significantly affected the joint toxicity of OPFRs.

The 2D-QSAR model should have a clear range of applications. The prediction of compounds using the 2D-QSAR model is reliable when the model is within its application domain. On the contrary, it is less reliable when the model is outside its application domain (Du et al. 2019). The Williams diagram was drawn based on standardized residual $\delta$ values and the lever $h_{i}$ values (Yang et al. 2020b). This can 
visually reflect the scope of model application, judge the reliability and robustness of the 2D-QSAR model, and identify the outliers and influential compounds. The formula for the standardized residual $\delta$ and lever value $h_{i}$ used is as follows:

$$
\begin{gathered}
\delta=\frac{Y_{\text {exp }}-Y_{\text {pre }}}{\sqrt{\sum\left(Y_{\text {exp }}-Y_{\text {pre }}\right)^{2} /(n-p-1)}} \\
h_{i}=X_{i}\left(X^{T} X\right)^{-1} X_{i}^{T}
\end{gathered}
$$

where $Y_{\text {exp }}$ and $Y_{\text {pre }}$ represent the experimental and the predicted values of the target molecules, respectively, $n$ represents the number of target molecules, $p$ is the number of model molecular descriptors, $X_{i}$ represents the matrix of $\mathrm{i}^{\text {th }}$ target compound descriptor, $X$ is the matrix of all target compound descriptors, $X^{T}$ and $X_{i}{ }^{T}$ represent the transpose matrices of $X$ and $X_{i}$, respectively. The warning lever $h^{*}$ is the limit value of $X$ and the target molecules with $h_{i}<h^{*}$ are considered as the normal value of the structure. On the contrary, it is regarded as the abnormal value of the structure when $h_{i}<h^{*}$, where $h^{*}$ is defined as:

$$
h^{*}=3(p+1) / n
$$

where $n$ represents the number of compounds, and $p$ represents the number of the model molecular descriptors.

The parameters that significantly affected the joint toxicity of OPFR molecules in the special population were determined by calculating the sensitivity parameters (Du et al. 2019). The sensitivity coefficient $\left(S C_{i}\right)$ is the ratio of the relative change of the predicted value to the relative change of the input parameter and was calculated according to the following equation (4),

$$
S C_{i}=\left(\frac{\Delta Y_{i}}{Y_{i}}\right) /\left(\frac{\Delta X_{i}}{X_{i}}\right)
$$

where $S C_{i}$ is the sensitivity coefficients of the $\mathrm{i}^{\text {th }}$ parameter, $\Delta X_{i /} X_{i}$ represents the rate of change of the $\mathrm{i}^{\text {th }}$ parameter, and $\Delta Y_{i /} Y_{i}$ is the rate of change of the joint toxicity of 
OPFR molecules.

\subsection{Recommended CFS to alleviate the combined toxicity of OPFRs in pregnant} women -- MD method based on Taguchi experiment design

In this study, we selected 15 regular high protein-rich food items (milk, eggs, and soybean milk), fresh fruits and vegetables (orange, carrot, broccoli, spinach, grapes, jujube, apple, and kiwi fruit), grains (black rice and oat), and drinks (honey and cubilose) that are recommended to pregnant women. The main nutrients present in each food item were considered as external conditions, and their influence on the binding affinity of OPFRs molecules (TCEP, TPHP, and TDCPP) to JTR protein was measured by MD simulations. The MD method assisted by $\mathrm{L}_{32}\left(2^{8}\right)$ Taguchi experiment design was used to further screen the CFS that would be beneficial in reducing the human health risks of OPFRs in pregnant women. The $\mathrm{L}_{32}\left(2^{8}\right)$ Taguchi experimental design was conducted by selecting eight complementary food items (milk (A), egg (B), orange (C), spinach (D), grape (E), jujube (F), apple (G), and kiwi fruit $(\mathrm{H})$ ) that effectively reduced the OPFRs molecular joint toxicity (the reduction rate was between $10.74 \%-44.20 \%$ ) as the variables to generate the orthogonal experimental method. Taguchi experimental design is a special orthogonal experimental method in which fewer experiments are required to analyze a large number of variables (Castorena-Cortés et al. 2009). OPFR molecules and JTR protein complex were placed in a water cube box with a side length of $15 \mathrm{~nm}$, and the nutrients of the complementary food items were added to the constructed water cube box. The MD simulations of the joint toxicity of OPFRs molecules under different CFS were carried out according to the 32 orthogonal experimental groups generated (Table S2). Factorial analysis was then used to determine the CFS that could minimize the joint toxicity of OPFRs in the special population according to the 
binding free energy.

\section{Results and discussion}

\subsection{Joint toxicity mechanism of OPFRs molecules based on 2D-QSAR model}

The various parameters of OPFRs molecules used to construct the 2D-QSAR model are shown in Table S1. The joint toxicity of OPFRs molecular reproductive toxicity, neurotoxicity and ED toxicity were taken as the dependent variable, while the molecular structure parameters were considered to be the independent variables. The independent variables that significantly affected the joint toxicity of OPFRs were screened by stepwise regression method in SPSS, and the 2D-QASR model between the OPFRs molecular joint toxicity and its parameters was constructed. According to the 2D-QASR model, we studied the influence mechanism of the parameters on the OPFRs molecular joint toxicity.

Taking Considering the value $\mathrm{T}$ (the absolute value of binding free energy between OPFRs molecules and the JTR complex) of reproductive toxicity, neurotoxicity, and ED joint toxicity as the dependent variable, the 2D-QSAR model equation for the joint toxicity of OPFR molecules was as follows:

$$
T=14.74-0.897 Q_{Y Z}+0.963 E_{L U M O}-1.372 E G+6.735 \text { Raman }-
$$

$$
(C-O)_{S V F}
$$

The R-value of the 2D-QSAR model was $0.85(>0.8)$, and the Sig value was 0 (<0.05). Sig represents the significance at $\mathrm{P}=0.05$. The 2D-QSAR model passed the significance test, indicating that the parameters selected in the equation of the $2 \mathrm{D}$ QSAR model were related to the joint toxicity of the OPFR molecules. The $R_{\text {adj }}$ value of the 2D-QSAR model was $0.76(>0.6), R_{a d j}$ represents the determination coefficient of the 2D-QSAR model after the calibration of the internal validation parameters and the $R M S E_{T R}$ representing the root mean square error value met all the desired 
requirements. Thus, the 2D-QSAR model showed a good fitting degree (Golbraikh et al. 2020). The $Q_{L O O}^{2}$ value of the $2 \mathrm{D}-\mathrm{QSAR}$ model was $0.85(>0.6)$ and represented the cross-validation coefficient, indicating that the model had good stability (Qin et al. 2013). The calculated $R_{\text {test }}^{2}$ value of the 2D-QSAR model was $0.72(0.6)$, suggesting that the model had a strong external prediction ability (Roy et al. 2009).

The linear fitting diagrams of the OPFRs molecular predicted values and experimental values of the training set, the test set, and William's diagram within the application domain of the 2D-QSAR model equation are shown in Figure 1. The predicted and the experimental values of the training and test sets in the 2D-QSAR model were in good agreement with each other. The scope of application was determined by the lever alert values $h^{*}$ and $\delta$. The OPFRs molecules (15 molecules as training set and five molecules as the test set) used for constructing the 2D-QSAR model were introduced into equation (1) to calculate $h^{*}$ and $\delta$. The $h^{*}$ value was 0.75 (X-coordinate) and the $\delta$ value was \pm 3 (Y- coordinate) (Yang et al. 2020b). All the results of the 2D-QSAR model were within the acceptable range, indicating that the 2D-QSAR model was robust and had a wide range of applications. The model was also reliable in predicting the joint toxicity of similar molecules.

\section{Place Fig. 1 here}

The geometric parameter-quadrupole moment $\left(Q_{Y Z}\right)$, electronic parameterminimum orbital energy $\left(E_{L U M O}\right)$, energy gap (EG), and spectrogram parameterRaman C-O stretching vibration frequency ( Raman- $\left(C-O_{S V F}\right)$ of OPFRs molecules played important roles in the joint toxic effects. In order to further illustrate the influence of these parameters on the joint toxicity of OPFRs molecules, a sensitivity analysis was conducted for the above four parameters by using equation (5). Each parameter was increased by 10\%, 20\%, 30\%, 40\%, and 50\%. The influence 
trend and significance of each parameter on the joint toxicity were expressed by relative sensitivity, and the sensitivity coefficient value of each parameter calculated by the change of parameters is shown in Table 1.

\section{Place Table 1 here}

By comparing the absolute values of the sensitivity coefficients, it was found that the effect of the variable parameters on the joint toxicity of OPFRs molecules acted in the following trend: $E_{L U M O}>\operatorname{Raman}-\left(C-O_{S V F}\right)>\mathrm{EG}>Q_{Y Z} \cdot E_{L U M O}$ appeared as the important parameter that significantly influenced the joint toxicity of OPFRs molecules and had a positive coefficient value (in equation 5), indicating that it positively affected the toxicity of OPFRs. This implied that as the value of $E_{L U M O}$ was increased, the absolute value of the binding free energy of OPFRs molecules and JTR complex also increased subsequently, thereby increasing the joint toxicity of OPFRs molecules. Moreover, $E_{L U M O}$ represented the electrophilicity of compounds (Liu et al. 2019), in other words, the electron affinity of OPFRs molecules is considerably affected the joint toxic effect of OPFRs on the JTR proteins in the special population. OPFRs are electrophilic in nature and thus have strong binding affinities for the biomolecules. During ligand binding to the receptor, $E_{\mathrm{LUMO}}$ represents the electric field properties around the binding sites of OPFRs molecules and toxic receptor proteins. Therefore, a change in the electric field around the binding sites can be considered to alter the binding affinities of OPFRs and toxic receptor proteins; thus, reducing the OPFRs molecular toxicity. Previous studies have shown that target receptor proteins involved in various biological activities have high specificity and selectivity for ligands with specific structures or molecular force fields (Jones et al. 2021; Gong et al. 2019). Therefore, we considered adding other ligands into the compound system of OPFRs molecules and JTR complex, and by controlling the field 
properties around the binding sites of OPFRs and toxic receptor proteins, the competitive binding between multiple ligands was regulated; thus, reducing the binding affinity between OPFRs molecules and JTR proteins, hence the joint toxicity of OPFRs.

\subsection{Human health risk regulation of special population exposed to OPFRs}

\subsubsection{Screening of CFSs based on MD simulations to regulate human health risks}

\section{in pregnant women}

Dietary intake is a potential pathway of human exposure to OPFRs. Zhang et al. investigated the concentrations of typical OPFRs in 50 varieties of rice and 75 varieties of common food in China and found that the concentration of OPFRs was the highest in rice (Zhang et al. 2016). The intake of meat and fish may be related to higher DPP and BDCPP levels (Thomas et al. 2017). Therefore, in this study, 15 complementary food items with low OPFRs content and regular diet suggested during pregnancy were selected to develop a recommended CFS. The main nutrients in complementary food items were added into the complex system of OPFRs and JTR protein and the competitive combination of nutrients and OPFRs molecules was used to restrict or reduce the human health risks of OPFRs. Various supplements have been used in the past to improve the toxicity risks of biological receptors exposed to contaminants (Zhang et al. 2018; Rajabiesterabadi et al. 2020; Yilmaz, 2020). The binding of OPFRs molecules to JTR in the special population was a key step in its joint neurotoxicity, reproductive toxicity, and ED toxicity (Chen et al. 2015; Sun et al. 2016; Baldwin et al. 2017; Gu et al. 2018). TCEP, TPHP, and TDCPP were the most important OPFRs contaminants detected in the environment and pregnant women. MD simulations were used to simulate the influence of the binding ability of major nutrients in each complementary food items and OPFRs to JTR protein. The 
recommended CFS beneficial to reduce the health risks in the special population exposed to OPFRs were screened out.

The main nutrients present in milk are $\beta$-lactoglobulin, $\alpha$-lactoalbumin, and milk fat globule membrane (MFGM) protein; in the egg are ovalbumin (OVA) and ovotransferrin (OVT); in the soybean milk are plant protein, vitamin B1, vitamin B3, and niacin; in the orange are vitamin $\mathrm{C}$ and lycopene; in carrots are vitamin $\mathrm{A}$ and folic acid; in the broccoli are vitamins A, B, C, and $\mathrm{K}$; in the spinach are vitamin A and $\mathrm{B}$; in grapes are vitamin $\mathrm{A}$ and $\mathrm{B}$ and anthocyanin; in the jujube are vitamin $\mathrm{A}, \mathrm{B}$, $\mathrm{C}$, and $\mathrm{E}$; in the apple are vitamin $\mathrm{C}$, apple polyphenols, malic acid, anthocyanin, lycopene, and niacin; in the kiwi fruit are vitamin A, C, and E; in black rice in the cereal category are vitamin A and B and folic acid, in oats are vitamin B1, B2, and E and folic acid. The main nutrients found in honey as a drink are vitamin B and C, and in the cubilose are sialic acid and epidermal growth factor. The binding free energies of OPFRs molecules and JTR protein complexes after the addition of main nutrients found in complementary food items were as follows: $-62.763 \mathrm{~kJ} / \mathrm{mol},-65.059 \mathrm{~kJ} / \mathrm{mol}$, $-55.695 \mathrm{~kJ} / \mathrm{mol},-108.303 \mathrm{~kJ} / \mathrm{mol},-95.456 \mathrm{~kJ} / \mathrm{mol},-86.659 \mathrm{~kJ} / \mathrm{mol},-99.629 \mathrm{~kJ} / \mathrm{mol},-$ $108.373 \mathrm{~kJ} / \mathrm{mol},-68.857 \mathrm{~kJ} / \mathrm{mol},-84.325 \mathrm{~kJ} / \mathrm{mol},-54.174 \mathrm{~kJ} / \mathrm{mol},-78.35 \mathrm{~kJ} / \mathrm{mol},-$ $102.828 \mathrm{~kJ} / \mathrm{mol},-96.725 \mathrm{~kJ} / \mathrm{mol}$, and $-89.651 \mathrm{~kJ} / \mathrm{mol}$. The results showed an increase in the absolute values of the binding energies of OPFRs molecules and the JTR protein complexes in the presence of 11 complementary food items (milk, egg, soybean milk, orange, spinach, broccoli, grapes, jujube, apple, kiwi fruit, and cubilose) (Figure 2). However, the opposite was true in the case of milk (A), egg (B), orange $(C)$, spinach $(D)$, grape $(E)$, jujube $(F)$, apple $(G)$, and kiwi fruit $(H)$ where the absolute values of binding energies of OPFRs molecules and JTR protein complex decreased significantly within the range of $10.74 \%$ to $44.20 \%$. Therefore, it was 
suggested that the above eight complementary food items could significantly reduce the combined toxicity of OPFRs molecules (TCEP, TPHP, and TDCPP) in pregnant women.

In the above eight complementary food items, except milk and eggs, the rest of them were (fruits and vegetables) edible plant supplements. Previous studies showed that medicinal plants and their extracts had antioxidant effects when varieties of fish were exposed to toxic substances such as heavy metals $\mathrm{Cu}$ and $\mathrm{Zn}$, bisphenol $\mathrm{A}$, etc. (Abdel-Tawwab et al. 2018; Hamed and Abdel-Tawwab, 2017; Hoseini et al. 2018a, 2018b). Hoseini et al. found that myrcene or menthol inclusive diet inhibited ammonia-induced tissue damage, anemia, and oxidative stress responses in common carps (Hoseini et al. 2019). Also, plant supplements such as garlic (Yousefi et al. 2020), artemisia annulis (Taheri Mirghaed et al. 2020), olea europea (Rajabiesterabadi et al. 2020), ceratonia silique (Yilmaz, 2020), phytochemicals such as 1,8 cineole (Taheri Mirghaed et al. 2019), myrcene (Hoseini et al. 2019), menthol (Hoseini et al. 2019), and berberine (Chen et al. 2016) helped biological receptors exposed to a variety of toxic substances to resist their biotoxicity. The results of these studies supported our observations and were consistent with the efficacy of plant supplements used in this study.

Place Fig. 2 here

\subsubsection{Recommendation of CFS based on Taguchi experimental design to improve}

\section{human health risks in special population}

MD results showed that milk (A), egg (B), orange (C), spinach (D), grape (E), jujube $(F)$, apple $(G)$, and kiwi fruit $(H)$ could significantly reduce the joint toxicity of OPFRs molecules (TCEP, TPHP, and TDCPP) in special population. The above eight supplemental foods were considered as the experimental variables, and the binding 
free energies of TCEP, TPHP, and TDCPP molecules and the JTR protein complex were calculated by MD simulations according to the complementary food combinations generated by the $\mathrm{L}_{32}\left(2^{8}\right)$ Taguchi orthogonal experimental design (Figure 3).

\section{Place Fig. 3 here}

In Figure 3, the dark blue color represented the presence of complementary food whereas, the light blue color represented the absence. It was observed that the heat map of scheme 33 (blank group, without complementary food items) had the darkest color. The absolute values of binding free energies of 32 groups of CFS were lower than that of scheme 33, indicating that all the CFS were able to reduce the binding ability of OPFRs and the JTR complex protein. The absolute values of the binding free energies of 32 groups of CFS were changed in the range of $-14.16 \%--85.19 \%$, in comparison to the blank group. When milk (A), orange (C), grape (E), jujube (F), and kiwi fruit $(\mathrm{H})$ were all added at the same time (the main nutrition: $\beta$-lactoglobulin, $\alpha$ lactoalbumin, MFGM protein, vitamin A, B, C, D, and E, anthocyanin, and lycopene), the binding ability of TCEP, TPHP, and TDCPP to JTR protein in special population was significantly reduced ( $85.19 \%$ lower than that in the blank group); consequently, the health risks of OPFRs to humans was significantly reduced.

The absolute values of binding energies of TCEP, TPHP, and TDCPP with the JTR protein in the special populations were taken as the response value and the factorial analysis of Taguchi experimental design was performed subsequently. As the absolute value of average binding free energy was decreased, consequently, the binding affinity between OPFRs molecules and the JTR protein and the toxicity of the OPFRs in special population was also decreased. Hence, according to Table 2, the recommended CFS was : milk (A), orange (C), spinach (D), and jujube (F), their main 
nutrients were $\beta$-lactoglobulin, $\alpha$-lactoalbumin, MFGM protein, Vitamin A, B, C, D, E, lycopene). The binding free energy of TCEP, TPHP, and TDCPP with the JTR protein $(-8.563 \mathrm{~kJ} / \mathrm{mol})$ was calculated in the presence of recommended CFS. When compared with the binding free energy of the blank group, the change rate of the binding free energy under recommended CFS was $-91.18 \%$. It was the lowest absolute value of binding energy among all CFS and was consistent with the results of the Taguchi experimental design factor analysis. The main nutrition of CFS could reduce the combined toxicity of OPFRs to the maximum extent $(85.19 \%)$ in 32 groups of Taguchi experimental design schemes (comprised of milk (A), orange (C), grape (E), jujube (F), and kiwi fruit $(\mathrm{H})$ ) and the recommended CFS containing milk (A), orange (C), spinach (D) and jujube (F) (sources of main milk protein, vitamins, and plant pigments). These results indicated that $\beta$-lactoglobulin, $\alpha$-lactoalbumin, MFGM protein, vitamins $\mathrm{A}, \mathrm{B}, \mathrm{C}, \mathrm{D}$, and $\mathrm{E}$, and plant pigments were the main factors that significantly reduced the binding ability of OPFRs to the JTR protein in the special population.

Yousef et al. evaluated the immune stimulation, and anti-inflammatory effects of Roselle added to the diet under normal conditions and ammonia exposure on rainbow trout (Oncorhynchus mykiss). Roselle contains a lot of natural pigments such as multivitamins and anthocyanins. The results showed that Roselle supplementation significantly increased the white blood cells, plasma total immunoglobulins, alternative complement pathway (ACH50), bactericidal activity, and skin mucus/plasma lysozyme activity. It was demonstrated that Roselle was capable of augmenting immune response and mitigate inflammation in rainbow trout, leading to better health following ammonia toxicity (Yousefi et al. 2021). Supplementation of vitamin $\mathrm{C}$ in feed could improve iron toxicity in aquatic Ictalurus punctatus (Yadav et 
al. 2020). The antioxidant protective effects of multi-vitamins have been shown to counteract the toxicity of hydrophilic metals such as lead $(\mathrm{Pb})$ in many species of fish (Nourian et al. 2019; Shahsavani et al. 2017). Besides, Harsij et al. (2020) found that fish fed with diets containing nanoselenium, vitamins $\mathrm{C}$ and $\mathrm{E}$, and antioxidants and exposed to sublethal ammonia showed significantly better growth performance, immune and antioxidant responses than those in the control group. All of these studies have shown that the dietary plants rich in vitamins and natural pigments can reduce the toxicity of the recipient organisms exposed to a variety of toxic materials. The above studies supported our results and confirmed that vitamin A, B, C, D, and E and plant pigments screened in this study were the main factors that significantly reduced the binding ability of OPFRs to the JTR protein in special populations.

\section{Place Table 2 here}

In accordance with the response value (absolute value of binding free energy), the CFS for reducing the binding affinity of OPFRs molecules and JTR followed the sequence: egg $(B)>$ orange $(C)>$ grape $(E)>$ apple $(G)>$ milk $(A)>$ fresh jujube $(F)>$ spinach $(\mathrm{D})>$ kiwi fruit $(\mathrm{H})$. The average binding free energy analysis showed that out of the top three complementary food items in the above sequence, i.e., egg (B), orange $(\mathrm{C})$, and grape $(\mathrm{E})$, the addition of orange only could reduce the binding affinity between OPFRs molecules and the JTR. In 32 groups of the Taguchi experiment scheme, the schemes 10, 12, 26, and 28 met the above-mentioned requirements, where CFS contained only orange (C) and no egg (B) and grape (E). The absolute value of binding free energy of OPFRs molecules and JTR in the presence of the above-mentioned complementary foods was in the range of 58.84\% $78.58 \%$, lower than that of the blank group. On the contrary, the schemes $5,7,21$, and 23 (with egg (B) and grape (E) and without oranges (C)) had a lower absolute value of 
binding free energy $(18.52 \%-34.72 \%)$ of OPFRs molecules and JTR than that of the blank group. The reduction degree of the absolute value of binding free energy was much less than that of the CFS determined according to the average response values and the rank of the factorial analysis results, indicating that the factorial analysis results of the Taguchi experimental design were representative and reliable. Therefore, according to the results of factorial analysis of Taguchi experimental design, the recommended CFS with the milk (A), orange (C), spinach (D), and jujube (F) (main nutrient: $\beta$-lactoglobulin, $\alpha$-lactoalbumin, MFGM protein, and vitamins) significantly reduced the binding free ability of OPFRs to the toxic receptor protein in the special population. The main proteins present in the milk and vitamins were the recommended complementary nutrient combinations for the prevention of health risks in special populations exposed to OPFRs. However, with the presence of milk (A), eggs (B), spinach (D), and apple (G) (primary nutrients: $\beta$-lactoglobulin, $\alpha$ lactoalbumin, MFGM protein, OVA, OVT, vitamin, plant pigments, apple polyphenols, and malic acid) at the same time, the absolute value of binding free energy of TCEP, TPHP, and TDCPP with JTR protein was minimally decreased (only $14.16 \%)$. Therefore, it was not recommended to consume OVA, OVT, $\beta$ lactoglobulin, $\alpha$-lactoglobulin, and MFGM protein together with the complementary foods rich in vitamins, plant pigments, apple polyphenols, and malic acid. In addition, although no dietary factors were significantly associated with OPFRs and their metabolite concentrations, some studies showed that increased dairy product and fresh intake could be associated with the lower levels of OPFRs metabolites DPP, BDCPP, and ip-DPP (M.B. Thomas et al. 2017) and supported the introduction of the CFS (with milk, orange, spinach and jujube present at the same time) recommended in the present work capable of significantly reducing the binding affinity of OPFRs with the 
JTR protein.

3.3 Analysis of the mechanism for the improvement of OPFRs joint toxicity effects by recommended CFS in special population

\subsubsection{Mechanism analysis for the improvement of OPFRs molecular} neurotoxicity, reproductive toxicity, and ED toxicity under recommended CFS

To investigate the toxic effects that played a major role in joint toxicity in pregnant women exposed to OPFRs, three OPFRs molecules (TCEP, TPHP, and TDCPP) were docked with the neurotoxic receptor, reproductive toxic receptor, and endocrine disrupting toxic receptors, respectively. Then, each molecule of TCEP, TPHP and TDCPP was docked with neurotoxic receptor, reproductive toxic receptor and endocrine disrupting toxic receptor in sequence. The binding free energies of 12 groups of docking complexes were calculated by MD simulations, and their absolute values are shown in Figure 4. The darkest shades of red, green, and blue colors in the outermost part of the annular histogram in Figure 4 represented the absolute values of binding free energies of the three OPFRs molecules with the JTR complex. The absolute value of binding energy represented the binding affinity of OPFRs and JTR protein. The colors varying from dark to light in the legend represented the binding affinity of different ligands and each toxic receptor in the annular histogram.

\section{Place Fig. 4 here}

It was observed from Figure 4 that the absolute value of binding free energy of three OPFRs molecules with the JTR complex, neurotoxic receptor, reproductive toxic receptor, and endocrine disrupting toxic receptor were 97.089, 98.352, 116.27, and 89.089, respectively. The toxicity increases with the increase in absolute values of binding free energies. The results showed that the toxicity effect of OPFRs molecules and reproductive toxic receptor complex was most prominent and increased by 
$19.76 \%$ in comparison to the joint toxicity effect of OPFRs molecules and JTR complex. While the toxicity of TCEP, TPHP, and TDCPP with neurotoxic receptors increased slightly (1.30\%), it decreased slightly with ED toxic receptor (8.24\%), suggesting that the reproductive toxicity of OPFRs molecules was greater than neurotoxic and endocrine disrupting toxicity and played a dominant role in the joint toxicity. The results showed that the absolute values of binding free energies of TCEP and TPHP with reproductive toxicity receptor (67.876 and 60.612) were higher than those with neurotoxicity receptor (56.238 and 48.971) and endocrine disrupting toxicity receptor (48.502 and 42.640 ). It can be said that the reproductive toxicity of TCEP and TPHP molecules was greater than neurotoxicity and endocrine toxicity. On the contrary, the TDCPP molecule showed significant neurotoxicity in comparison to TCEP and TPHP, which could be related to the strong neurotoxicity of the TDCPP molecule itself (Ali et al. 2016; Wang et al. 2015; Dishaw et al. 2011). The binding free energy results of the three OPFRs molecules in simultaneous or sequential binding with neurotoxicity receptor, reproductive toxicity receptor, and endocrine toxicity receptor showed that the effect of reproductive toxicity was significantly greater than that of the other two toxic effects and was the main influencing factor in the joint toxicity. Therefore, it was necessary to explore the regulatory mechanism of the joint multi-toxicity in terms of reproductive toxicity.

The recommended CFS proposed in this study could significantly reduce the joint toxicity of OPFRs in the special population (decreased by 91.18\%). To investigate whether the recommended CFS also had a significant low health risk effect on the main toxicity (reproductive toxicity) of the joint toxic effects, the binding free energies of OPFRs with the reproductive toxic receptor, neurotoxicity receptor, and endocrine toxic receptor were calculated under the recommended CFS. 
The results showed that the absolute values of binding free energies of three OPFRs with reproductive toxicity receptor, neurotoxicity receptor, and endocrine toxicity receptor were 20.37, 52.79, and 47.49. However, without recommended CFS, the binding affinities of OPFRs to reproductive toxicity receptor (116.27), neurotoxicity receptor (98.53), and endocrine disrupting toxic receptor (89.09) were decreased by $82.48 \%, 46.55 \%$, and $46.69 \%$, respectively. The ratio of reduction in reproductive toxicity, neurotoxicity, and endocrine toxicity was 4.69: $2.65: 2.66$. The results showed that the recommended CFS could not only significantly reduce the joint toxicity of OPFRs, but also effectively reduce the single effects of reproductive toxicity, neurotoxicity, and endocrine toxicity, and it was worth mentioning that the reproductive toxicity in the joint toxicity decreased the most. Effects of reproductive toxicity on animals mainly included decreased pregnancy rate, miscarriage, stillbirth, teratogenesis, and fetal developmental disorders (Guerby et al. 2021). Therefore, reproductive toxicity could be considered as a major health risk factor in pregnant women during delivery. The presence of the recommended CFS reduced reproductive toxicity by $176.98 \%$ and $176.32 \%$ when compared with the reduction in neurotoxicity and endocrine toxicity, respectively. This indicated that the recommended CFS had a significant positive effect in the improvement of reproductive toxicity as the major health risk in pregnant women.

\subsubsection{Mechanism analysis of the competitive binding of nutrients and OPFRs} molecules with JTR complex

Since main nutrients such as $\beta$-lactoglobulin, $\alpha$-lactoalbumin, MFGM protein, vitamin A, B, C, D, and E, and plant pigments (lycopene and anthocyanin) in CFS significantly reduced the binding ability of OPFRs to JTR, hence, the competitive binding mechanism of main nutrients and OPFRs molecules with the JTR complex 
was determined by molecular docking and DFT. Varieties of hydrophobic organic contaminants (HOCs) were concentrated in the zucchini plants and contaminated the agricultural soil through the roots of the plants. Major latex-like proteins (MLPs) in the zucchini family played an important role in binding with HOCs. Fujita et al. inhibited the binding of HOCs and MLPs by introducing the compounds with indoles and quinazolines-like structures to facilitate easy binding to MLP. When zucchini plants were cultivated in the contaminated soil with $1.25 \mathrm{mmol} / \mathrm{kg}$ pyrene and 12.5 $\mathrm{mmol} / \mathrm{kg}$ dieldrin, the concentration of pyrene and dieldrin in xylem sap was significantly reduced by $30 \%$ and $15 \%$, respectively. It was demonstrated that the pesticides bonded to MLPs, competitively inhibited the binding of MLPs to pyrene and dieldrin in roots, resulting in the reduction of agricultural soil pollution caused by HOCs (Fujita et al. 2020). PUM2 could facilitate the stemness of breast cancer cells by competitively binding to neuropilin-1 3' UTR with miR-376a (Zhang et al. 2019). The above studies have shown that the competitive binding between different ligands could achieve the optimal regulation of ligand-receptor binding and accomplish the established goals. Therefore, it can be speculated that when ligands were added to the OPFRs - JTR complex system, nutrients modified the nature of the molecular force field around the target binding spot of ligand molecules (including nutrients and OPFRs molecules) and JTR. Consequently, nutrients competitively inhibited the binding of OPFRs to JTR in special populations and changed the binding affinity of OPFRs and JTR, resulting in a subsequent reduction in the human health risks in special populations exposed to OPFRs.

Firstly, nutrients that significantly reduced the binding affinity between OPFRs and JTR protein and the corresponding OPFRs molecules were sequentially docked with JTR by the molecular docking method. The total score (TS) of ligand molecules 
docked with receptor protein represented their binding affinities. As the TS increases, the binding affinity of ligands and receptors increases. In Figure 5, the TS of vitamin A, B, C, D, and E, lycopene, and anthocyanin docked with JTR complex was the Z value of spherical coordinate with a radius equal to one. (The TS of $\beta$-lactoglobulin, $\alpha$-lactoalbumin, and MFGM protein docked with JTR was not considered, because $\beta$ lactoglobulin, $\alpha$-lactoalbumin, and MFGM protein were directly docked with the JTR protein as a protein complex; thus TS could not be calculated.) The TS of three OPFRs molecules (TCEP, TPHP, and TDCPP) docked with JTR complex was the Z value of spherical coordinate, and the radius was equal to 1.5. The TS of the nutrients docked with JTR slightly fluctuated in the range of $-25.63 \%-16.48 \%$, in comparison to the TS score of the three OPFRs molecules. The TS of $\beta$-lactoglobulin, $\alpha$ lactoalbumin, MFGM protein, vitamin A, B, C, D, and E, lycopene, anthocyanin, and the three OPFRs molecules docked with JTR was $81.01 \%$ higher than that of the only three OPFRs molecules docked with the JTR, indicating that when $\beta$-lactoglobulin, $\alpha$ lactoalbumin, MFGM protein, vitamin A, B, C, D, and E, lycopene, anthocyanin were present along with the three OPFRs, the binding affinity of nutrients to the JTR protein was better than that of only OPFRs. It can be speculated that OPFRs molecules and the nutrients had competitive binding with the JTR protein. Furthermore, the coexistence of these ten nutrients and OPFRs molecules facilitated the easier binding of nutrients to JTR and occupancy of more target binding spots of JTR by nutrients and reduced or prevented the binding of OPFRs molecules to JTR protein, thereby reducing the joint toxicity of OPFRs in special population.

\section{Place Fig. 5 here}

In the docking system of OPFRs molecules and JTR protein, OPFRs molecules were taken as the object of study. According to the force field diagram of OPFRs and 
nutrients docked with JTR (Figure S1), the main non-bonded interactions acted between OPFRs molecules and amino acid residues of the JTR protein were hydrogen bonding and charged or polar interactions, which played an important role in the stability of the ligand-receptor protein complex. While, in the presence of nutrients of the CFS when the nutrients and OPFRs were simultaneously docked with the JTR protein, van der Waals forces with low binding ability was the major non-bonded interaction between OPFRs molecules and the amino acid residues of the JTR protein. This indicated that the presence of nutrients changed the nature of the force field of the target binding spot of the OPFRs-JTR docking system (from hydrogen bond and electrostatic force with the strong binding ability to van der Waals force with small binding ability) (Jiang and Li, 2016; Qu et al. 2012). From the perspective of the total number of forces in the OPFRs-JTR docking system, TCEP, TPHP, and TDCPP generated 12, 24, and 18 non-bonded interactions with amino acid residues of JTR, respectively. However, when OPFRs molecules and multiple nutrients of CFS were simultaneously docked with the JTR protein, the number of non-bonded forces generated by TCEP remained the same but were decreased to 12 and 11 in the case of TPHP and TDCPP, respectively. In conclusion, the nutrients of the recommended CFS presented in the OPFRs-JTR complex altered the properties of the amino acid field of the OPFRs molecules.

According to the results of 2D-QSAR model, $E_{L U M O}$ was the main factor that significantly affected the joint toxicity of OPFRs. In other words, the electron affinity of OPFRs was the main factor affecting the toxic effects of OPFRs on JTR in the special population. Gaussian 09 was used to calculate the electronic parameter $E_{L U M O}$ of TCEP, TPHP, and TDCPP molecules and nutrients that could minimize the binding affinity of OPFRs molecules to the JTR. The $E_{L U M O}$ values of TCEP, TPHP, TDCPP, 
vitamin $\mathrm{A}, \mathrm{B}, \mathrm{C}, \mathrm{D}$, and $\mathrm{E}$, lycopene, and anthocyanin were $1.32,1.69,1.61,-0.07$, $0.75,-1.14,-0.19,-1.78,-2.45$, and -2.09 , respectively. The $E_{L U M O}$ of all the nutrients was significantly lower than that of OPFRs molecule. According to DFT, the $E_{L U M O}$ of a compound was related to its ionization potential. Moreover, it also characterized the binding sensitivity of a compound toward an organic nucleophile (JTR protein). JTR proteins preferred to bind to the molecules with low $E_{L U M O}$ (Karelson et al. 1996; Mumit et al. 2020). This explains the easy binding of the nutrients found in dairy products and fresh food to the receptor protein than OPFRs molecules due to the significantly lower value of $E_{L U M O}$ than OPFRs molecules, thus, altering the force field of amino acid around the OPFRs - JTR complex system to a greater extent and decreasing the binding effect of OPFRs to the target binding spot of the JTR. It is a common phenomenon that multiple ligands compete to bind to a receptor (Fujita et al. 2020; Jones et al. 2021). Wang et al. (2017) showed that among several strong non-bonded interactions of amino acids surrounding a ligand-receptor protein docking complex, the electrostatic force was the main force that kept the HSA-Ceviprex complex stable and targeted the receptor protein selectively bound to the ligand. These results were in complete agreement with our results, validating the effectiveness of the 2D-QSAR model, and thus, it was suggested that the joint toxicity of OPFRs in the special population could be controlled by regulating the intake of nutrients in complementary food.

\subsubsection{MD simulations of the OPFRs molecular metabolic process in the human} body under the recommended CFS

In humans and animals, once the activities of certain metabolic enzymes are induced and activated, the metabolism of toxic components is accelerated; thus, reducing the time for toxic components to accumulate in vivo and the toxicity of the 
690

691

692

693

694

695

696

697

698

699

700

701

702

703

704

705

706

707

708

pollutants. For example, Aconitum alkaloids were metabolized by the metabolic enzyme CYP450 into single-ester alkaloids with low toxicity (Park et al. 2016). Some metabolic enzymes belong to kinase, which can activate the toxicity of pollutants in vivo. For example, CYP3A65 is an important metabolic enzyme in zebrafish that activates BDE47 to cause developmental toxicity, resulting in delayed embryo hatching and abnormal embryonic neurodevelopment. This could be due to the decreased thyroxine levels and the subsequent destruction of thyroid hormone homeostasis through the up-regulation of Dio3A and Dio3B gene expressions by CYP3A65. However, it was found that CYP3A65 knockout could significantly improve the thyroid hormone homeostasis and reduce the toxic effect of BDE47 on zebrafish embryos (Yang et al. 2017).

Six metabolic kinases (thyroid hormone receptor $\left(\mathrm{TR} \alpha_{1}\right)$, retinoic acid receptor $\alpha$ $(\mathrm{RAR} \alpha)$, retinoid $\mathrm{X}$ receptor $(\mathrm{RXR} \alpha)$, pregnane $\mathrm{X}$ receptor $(\mathrm{PXR})$, and liver $\mathrm{X}$ receptor (LXR)) in pregnant women were selected to simulate the metabolic activation processes with OPFRs molecules by MD method. The activation processes were simulated with and without the recommended CFS. The OPFRs molecules bonded to the above six metabolic kinases could activate the toxicity of OPFRs in vivo, which in turn could inhibit or block normal biochemical reactions in the human body; thus, inducing hepatomegaly, thyroid hormone secretion disorder, and other toxic effects (Kojima et al. 2013; Belcher et al. 2014; Jiang et al. 2020). Therefore, it can be deduced that as the binding affinity between OPFRs and metabolic kinases decreases, the activation degree of OPFRs molecular toxicity also decreases thus, reducing the health risks of OPFRs in special populations.

MD simulations were carried out to calculate the binding free energy of OPFRs and six metabolic kinases receptors in the presence of the recommended CFS 
comprised of milk (A), orange (C), spinach (D), and jujube (F), as well as without them (Figure 6). The absolute value of binding free energies of OPFRs molecules and TR $\alpha 1, \mathrm{TR} \beta 1, \mathrm{RAR} \alpha, \mathrm{RXR} \alpha, \mathrm{PXR}$, and LXR in the presence of recommended CFS were decreased by $41.32 \%, 60.70 \%, 87.54 \%, 39.77 \%, 28.85 \%, 68.67 \%$, respectively, considering the binding energy values without the recommended CFS as the reference. These results verified that the recommended CFS could not only significantly reduce the joint toxicity of OPFRs in the special population but also reduce the binding affinity between OPFRs and metabolic kinases receptors, inhibiting the toxic effects of OPFRs. Hence, it can be anticipated that the recommended CFS had certain theoretical guiding significance to reduce the human health risk of OPFRs in pregnant women.

\section{Place Fig. 6 here}

\section{Conclusions}

In summary, the joint toxicity mechanism of OPFRs molecules in the special population was studied via integrated molecular docking and MD simulations based on the 2D-QSAR model, DFT, and Taguchi experiment design. Besides, the health risk regulation scheme of human exposure to OPFRs for the special population was presented, where the recommended CFS could theoretically reduce the joint effects of neurotoxicity, reproductive toxicity, and ED toxicity in the special population. The methods constructed in this study provided theoretical support for mitigating the potential health risks in the special population exposed to OPFRs in the environment. 


\section{References}

Abdel-Tawwab M, Sharafeldin KM, Ismaiel N.E.M (2018) Interactive effects of coffee bean supplementation and waterborne zinc toxicity on growth performance, biochemical variables, antioxidant activity and zinc bioaccumulation in whole body of common carp Cyprinus carpio L. Aquac. Nutr. 24, 123-130.

Adams S, Wiersielis K, Yasrebi A, Conde K, Armstrong L, Guo GL, Roepke TA (2020) Sex- and age-dependent effects of maternal organophosphate flame retardant exposure on neonatal hypothalamic and hepatic gene expression. Reproductive Toxicology 94, 65-74.

Ali N, Eqani SAMAS, Ismail IMI, Malarvannan G, Kadi MW, Albar HMS, Rehan M, Covaci A (2016) Brominated and organophosphate flame retardants in indoor dust of Jeddah, Kingdom of Saudi Arabia: Implications for human exposure. Sci. Total Environ. 569-570, 269-277.

Baldwin KR, Phillips AL, Horman B, Arambula SE, Rebuli ME, Stapleton HM, Patisaul HB (2017) Sex specific placental accumulation and behavioral effects of developmental Firemaster 550 exposure in Wistar rats. Sci Rep 7, 7118. http://dx. doi.org/10.1038/s41598-017-07216-6.

Belcher SM, Cookman CJ, Patisaul HB, Stapleton HM, (2014) In vitro assessment of human nuclear hormone receptor activity and cytotoxicity of the flame retardant mixture FM 550 and its triarylphosphate and brominated components. Toxicol. Lett. 228, 93-102.

Boyle M, Buckley JP, Quirós-Alcalá L, (2019) Associations between urinary organophosphate ester metabolites and measures of adiposity among U.S. Children and adults: NHANES 2013-2014. Environ. Int. 127, 754-763. https://doi.org/10. 1016/j.envint.2019.03.055.

Butt CM, Hoffman K, Chen A, Lorenzo A, Congleton J, Stapleton HM (2016) Regional comparison of organophosphate flame retardant (PFR) urinary metabolites and tetrabromobenzoic acid (TBBA) in mother-toddler pairs from California and New Jersey. Environ. Int. 94, 627-634.

Carignan CC, McClean MD, Cooper EM, Watkins DJ, Fraser AJ, Heiger-Bernays W, Stapleton HM, Webster TF, (2013) Predictors of tris(1,3-dichloro-2-propyl) phosphate metabolite in the urine of office workers, Environ. Int. 55, 56-61. 
https://doi.org/10.1016/j.envint.2013.02.004.

Castorena-Cortés G; Roldán-Carrillo T; Zapata-PeAsco I; Reyes-Avila J; Quej-Aké L; Marín-Cruz J; Olguín-Lora P (2009) Microcosm assays and Taguchi experimental design for treatment of oil sludge containing high concentration of hydrocarbons. Bioresource Technol. 100, 5671-5677.

Chen G, Jin Y, Wu Y, Liu L, Fu Z (2015) Exposure of male mice to two kinds of organophosphate flameretardants (OPFRs) induced oxidative stress and endocrine disruption. Environ. Toxicol. Phar. 40, 310-318.

Chen T, Yu D, Yang L, Sui S, Lv S, Bai Y, Sun W, Wang Y, Chen L, Sun Z, Tian L, Wang D, Niu P, Shi Z (2019) Thyroid function and decabromodiphenyl ethane (DBDPE) exposure in Chinese adults from a DBDPE manufacturing area. Environ. Int. 133, 105179.

Chen J, Wu N, Qu R, Xu X, Shad A, Pan X, Yao J, Bin-Jumah M, Allam AA, Wang Z, Zhu F (2020) Photodegradation of polychlorinated diphenyl sulfides (PCDPSs) under simulated solar light irradiation: Kinetics, mechanism, and density functional theory calculations. J. Hazard. Mater. 398, 122876.

Chu ZH, Li Y (2019) Designing modified polybrominated diphenyl ether BDE-47, BDE-99, BDE-100, BDE-183, and BDE-209 molecules with decreased estrogenic activities using 3D-QSAR, pharmacophore models coupled with resolution $\mathrm{V}$ of the 2(10-3) fractional factorial design and molecular J. Hazard. mater. 364, 151-162. DOI:10.1016/j.jhazmat.2018.10.027

Dishaw LV, Powers CM, Ryde IT, Roberts SC, Seidler FJ, Slotkin TA, Stapleton HM (2011) Is the PentaBDE replacement, tris (1,3-dichloro-2-propyl) phosphate (TDCPP), a developmental neurotoxicant? Studies in PC12 cells. Toxicol. Appl. Pharmacol. 256, 281-289.

Doherty BT, Hoffman K, Keil AP, Engel SM, Stapleton HM, Goldman BD, Olshan AF, Daniels JL (2019) Prenatal exposure to organophosphate esters and behavioral development in young children in the Pregnancy, Infection, and Nutrition Study. Neurotoxicology 73,150-160, https://doi.org/10.1016/j.neuro.2019.03.007.

Du MJ, Zhang D, Hou YL, Zhao XH, Li Y (2019) Combined 2D-QSAR, Principal Component Analysis and Sensitivity Analysis Studies on Fluoroquinolones' Genotoxicity, Int. J. Env. Res. Pub. He. 16, 4156. https://10.3390/ijerph16214156 Fan X, Kubwabo C, Rasmussen PE, Wu F (2014) Simultaneous determination of 
thirteen organophosphate esters in settled indoor house dust and a comparison between two sampling techniques, Sci. Total Environ. 491-492, 80-86. https://doi.org/10.1016/j.scitotenv.2013.12.127.

Frank F, Okafor CD, Ortlund EA (2018) The first crystal structure of a DNA-free nuclear receptor DNA binding domain sheds light on DNA-driven allostery in the glucocorticoid receptor, Sci. Rep. 8, 13497-13497

Fujita K, Kondoh Y, Honda K, Haga Y, Osada H, Matsumura C, Inui H, (2020) Pesticide treatment reduces hydrophobic pollutant contamination in Cucurbita pepo through competitive binding to major latex-like proteins. Environ. Pollut. $266,115179$.

Golbraikh A, Tropsha A (2002) Predictive QSAR modeling based on diversity sampling of experimental datasets for the training and test set selection. J. Comput. Aid. Mol. Des. 16, 357-369.

Gong F, Dong D, Zhang T, Xu W, (2019) Long non-coding RNA FENDRR attenuates the stemness of non-small cell lung cancer cells via decreasing multidrug resistance gene 1 (MDR1) expression through competitively binding with RNA binding protein HuR. Eur. J. Pharmacol. 853, 345-352. https://doi: 10.1016/j.ejphar.2019.04.022.

Gu YX, Yang Y, Wan B, Li MJ, Guo LH (2018) Inhibition of O-linked Nacetylglucosamine transferase activity in PC12 cells-A molecular mechanism of organophosphate flame retardants developmental neurotoxicity. Biochem. Pharmacol. 152, 21-33.

Guerby P, Fillion A, O'Connor S, Bujold E (2020) Heparin for preventing adverse obstetrical outcomes in pregnant women with antiphospholipid syndrome, a systematic review and meta-analysis. J. Gynecol. Obstet. Hum. 50, 101974. https://doi.org/10.1016/j.jogoh.2020.101974

Hamed HS, Abdel-Tawwab M (2017) Ameliorative effect of propolis supplementation on alleviating bisphenol-a toxicity: growth performance, biochemical variables, and oxidative stress biomarkers of Nile tilapia, Oreochromis niloticus (L.) fingerlings. Comp. Biochem. Phys. C. 202, 63-69.

Harsij M, Kanani HG, Adineh H (2020) Effects of antioxidant supplementation (nanoselenium, vitamin $\mathrm{C}$ and $\mathrm{E}$ ) on growth performance, blood biochemistry, immune status and body composition of rainbow trout (Oncorhynchus mykiss) under sub-lethal ammonia exposure. Aquaculture 521, 734942. 
https://doi.org/10.1016/J. aquaculture.2020.734942.

He C, English K, Baduel C, Thai P, Jagals P, Ware RS, Li Y, Wang X, Sly PD, Mueller JF (2018) Concentrations of organophosphate flame retardants and plasticizers in urine from young children in Queensland, Australia and associations with environmental and behavioural factors. Environ. Res. 164, 262270.

Hoffman K, Daniels JL, Stapleton HM (2014) Urinary metabolites of organophosphate flame retardants and their variability in pregnant women. Environ. Int. 63, 169-172, https://doi.org/10.1016/j.envint.2013.11.013.

Hoffman K, Butt CM, Chen A, Limkakeng AT, Stapleton HM (2015) High exposure to organophosphate flame retardants in infants: associations with baby products. Environ. Sci. Technol. 49, 14554-14559, https://doi.org/10.1021/acs.est. 5 b03577.

Hoseini SM, Hoseinifar SH, Van Doan H (2018a) Effect of dietary eucalyptol on stress markers, enzyme activities and immune indicators in serum and haematological characteristics of common carp (Cyprinus carpio ) exposed to toxic concentration of ambient copper. Aquac. Res. 49, 3045-3054. https://doi.org/10.1111/are.13765.

Hoseini SM, Taheri Mirghaed A, Iri Y, Ghelichpour M (2018b) Effects of dietary cineole administration on growth performance, hematological and biochemical parameters of rainbow trout (Oncorhynchus mykiss). Aquaculture 495, 766-772.

Hoseini SM, Yousefi M, Hoseinifar SH, Van Doan H (2019) Antioxidant, enzymatic and hematological responses of common carp (Cyprinus carpio) fed with myrcene- or menthol-supplemented diets and exposed to ambient ammonia. Aquaculture 506, 246-255.

Hou R, Xu Y, Wang Z (2016) Review of OPFRs in animals and humans: absorption, bioaccumulation, metabolism, and internal exposure research. Chemosphere 153, 78-90. http://dx.doi.org/10.1016/j.chemosphere.2016.03.003.

Liu Y, Dang Y, Feng X, Chen X, Yang C (2019) Promoting effect of Ni on the structure and electronic properties of $\operatorname{NixMo}(1-\mathrm{x}) \mathrm{S} 2$ catalyst and benzene adsorption: A periodic DFT study. Appl. Surf. Sci. 471, 607-614

Jiang L, Li Y (2016) Modification of PBDEs (BDE-15, BDE-47, BDE-85 and BDE126) biological toxicity, bio-concentration, persistence and atmospHeric longrange transport potential based on the pHarmacopHore modeling assistant with 
the full factor experimental design. J. Hazard. Mater. 307, 202-212.

Jiang Y, Yao X, Fan S, Gao Y, Zhang H, Huang M, Bi H (2020) Lipidomic profiling reveals triacylglycerol accumulation in the liver during pregnane $\mathrm{X}$ receptor activation-induced hepatomegaly. J. Pharmaceut. Biomed. 195, 113851. https://doi.org/10.1016/j.jpba.2020.113851

Jones R S, Chang J H, Flores M, Brecht E (2020) Evaluation of a Competitive Equilibrium Dialysis Approach for Assessing the Impact of Protein Binding on Clearance Predictions. J. Pharm. Sci-US. 110, 536-542. https://doi.org/10.1016/j.xphs.2020.09.012

Karelson M, Lobanov V S, Katritzky A R (1996) Quantum-chemical descriptors in QSAR/QSPR studies. Chem. Rev. 96, 1027-1043.

Kojima H, Takeuchi S, Itoh T, Iida M, Kobayashi S, Yoshida T (2013) In vitro endocrine disruption potential of organophosphate flameretardants via human nuclear receptors. Toxicology 314, 76- 83.

Kuwabara N, Oyama T, Tomioka D, Ohashi M, Yanagisawa J, Shimizu T, Miyachi H (2012) Peroxisome proliferator-activated receptors (PPARs) have multiple binding points that accommodate ligands in various conformations: phenylpropanoic acid-type PPAR ligands bind to PPAR in different conformations, depending on the subtype, J. Med. Chem. 55, 893-902

Li BB, Li CG, Qu RJ, Wu NN, Qi YM, Sun C, Zhou DM, Wang ZY (2020) Effects of common inorganic anions on the ozonation of polychlorinated diphenyl sulfides on silica gel: Kinetics, mechanisms, and theoretical calculations. Water Res. 186, 116358. DOI:10.1016/j.watres.2020.116358

Mao S, Liu S, Zhou Y, An Q, Zhou X, Mao Z, Wu Y, Liu W (2020) The occurrence and sources of polychlorinated biphenyls (PCBs) in agricultural soils across China with an emphasis on unintentionally produced PCBs. Environ. Pollut. 271, 116171. https://doi.org/10.1016/j.envpol.2020.116171

Meeker JD, Cooper EM, Stapleton HM, Hauser R (2013) Urinary metabolites of organophosphate flame retardants: temporal variability and correlations with house dust concentrations, Environ. Health. Persp. 121, 580-585, https://doi.org/10.1289/ehp.1205907.

Mumit M A, Pal T K, Alam M A, Islam MAAAA, Paul S, Sheikh M C (2020) DFT studies on vibrational and electronic spectra, HOMOeLUMO, MEP, HOMA, NBO and molecular docking analysis of benzyl-3-N-(2,4,5- 
trimethoxyphenylmethylene) hydrazinecarbodithioate. J. Mol. Struct. 1220, 128715 .

Nourian K, Baghshani H, Shahsavani D (2019) The effect of vitamin C on leadinduced plasma biochemical alterations in fish, Cyprinus carpio. Iran. J. Toxicol. $13,25-29$.

Ospina M, Jayatilaka N K, Wong LY, Restrepo P, Calafat A M (2018) Exposure to organophosphate flame retardant chemicals in the U.S. general population: Data from the 2013-2014 National Health and Nutrition Examination Survey. Environ. Int. 110, 32-41.

Park G, Kim K M, Choi S, Oh DS (2016) Aconitum carmichaelii protects against acetaminophen-induced hepatotoxicity via B-cell lymphoma-2 protein-mediated inhibition of mitochondrial dysfunction. Environ. Toxicol. Phar. 42, 218-225.

Percy Z, Vuong AM, Ospina M, Calafat AM, Guardia MJL, Xu Y, Hale RC, Dietrich KN, Xie C, Lanphear BP, Braun JM, Cecil KM, Yolton KA (2020) Organophosphate esters in a cohort of pregnant women: Variability and predictors of exposure. Environ. Res. 184,109255.

Qin LT; Liu SS; Xiao QF; Wu QS (2013) Internal and external validations of QSAR model: Review. Environ. Chem. 32, 1205-1211.

Qu R, Liu H, Feng M, Yang X, Wang Z (2012) Investigation on Intramolecular Hydrogen Bond and Some Thermodynamic Properties of Polyhydroxylated Anthraquinones. J. Chem. Eng. Data 57, 2442-2455.

Rajabiesterabadi H, Yousefi M, Hoseini SM (2020) Enhanced haematological and immune responses in common carp Cyprinus carpio fed with olive leaf extractsupplemented diets and subjected to ambient ammonia. Aquac. Nutr. 26, 763771.

Roy PP, Paul S, Mitra I, Roy K (2009) On two novel parameters for validation of predictive QSAR models. Molecules 14, 1600-1701.

Schneider JE, Brozek JM, Keen-Rhinehart E (2014) Our stolen figures: the interface of sexual differentiation, endocrine disruptors, maternal programming, and energy balance, Horm. Behav. 66, 104-119. https://doi.org/10.1016/j.yhbeh.2014. 03.011.

Schreder ED, Uding N, La Guardia MJ (2015) Inhalation a significant exposure route for chlorinated organophosphate flame retardants. Chemosphere 150, 499-504. http://dx.doi.org/10.1016/j.chemosphere.2015.11.084. 
Shahsavani D, Baghishani H, Nourian K (2017) Effect of thiamine and vitamin C on tissue lead accumulation following experimental lead poisoning in Cyprinus carpio. Iran. J. Vet. Sci. Technol. 9, 39-44. https://doi.org/10.22067/veterinary. v9i1.53864.

Shi J, Qu R, Feng M, Wang X, Wang L, Yang S, Wang Z (2015) Oxidative Degradation of Decabromodiphenyl Ether (BDE 209) by Potassium Permanganate: Reaction Pathways, Kinetics, and Mechanisms Assisted by Density Functional Theory Calculations. Environ. Sci. Technol. 49, 4209-4217.

Souza PCT, Textor LC, Melo DC, Nascimento AS, Skaf MS, Polikarpov I (2017) An alternative conformation of ER beta bound to estradiol reveals $\mathrm{H} 12$ in a stable antagonist position. Sci. Rep. 7, 3509-3509

Sun L, Xu W, Peng T, Chen H, Ren L, Tan H, Xiao D, Qian H, Fu Z (2016) Developmental exposure of zebrafish larvae to organophosphate flame retardants causes neurotoxicity, Neurotoxicol. Teratol. 55, 16-22.

Taheri Mirghaed A, Fayaz S, Hoseini SM (2019) Effects of dietary 1, 8-cineole supplementation on serum stress and antioxidant markers of common carp (Cyprinus carpio) acutely exposed to ambient ammonia. Aquaculture. 509, 8-15.

Taheri Mirghaed A, Paknejad H, Mirzargar SS (2020) Hepatoprotective effects of dietary Artemisia (Artemisia annua) leaf extract on common carp (Cyprinus carpio) exposed to ambient ammonia. Aquaculture. 527, 735443.

Tavoloni T, Stecconi T, Galarini R, Bacchiocchi S, Dörr AJM, Elia AC, Giannotti M, Siracusa M, Stramenga A, Piersanti A (2020) BFRs (PBDEs and HBCDs) in freshwater species from Lake Trasimeno (Italy): The singular case of HBCDs in red swamp crayfish. Sci. Total Environ. 758, 143585. https://doi.org/10.1016/j.scitotenv.2020.143585

Thomas MB, Stapleton HM, Dills RL, Violette HD, Christakis DA, Sathyanarayana S (2017) Demographic and dietary risk factors in relation to urinary metabolites of organophosphate flame retardants in toddlers. Chemosphere 185, 918-925.

Wei GL, Li DQ, Zhuo MN, Liao YS, Xie ZY, Guo TL, Li JJ, Zhang SY, Liang ZQ (2015) Organophosphate flame retardants and plasticizers: Sources, occurrence, toxicity and human exposure. Environ. Pollut. 196, 29-46.

Wang X, Guo X, Xu L, Liu B, Zhou L, Wang X, Wang D, Sun T (2017) Studies on the competitive binding of cleviprex and flavonoids to plasma protein by multispectroscopic methods: A prediction of food-drug interaction. J. Photoch. 
Photobio.B. 175, 192-199.

Wang Q, Lam JCW, Man YC, Lai NLS, Kwok KY, Guo YY, Lam PKS, Zhou B (2015) Bioconcentration, metabolism and neurotoxicity of the organophorous flame retardant 1,3-dichloro 2-propyl phosphate (TDCPP) to zebra fish. Aquat. Toxicol. 158, 108-115.

Wang J, Li J, Shi Z (2020) Dietary exposure assessment of a nursing mother-infant cohort to legacy and novel brominated flame retardants: Results of a 3-day duplicate diet study in Beijing, China, Chemosphere 254, 126843

Wiersielis KR, Adams S, Yasrebi A, Conde K, Roepke TA (2020) Maternal exposure to organophosphate flame retardants alters locomotor and anxiety-like behavior in male and female adult offspring, Horm. Behav. 122, 104759

Yadav AK, Sinha AK, Egnew N, Romano N, Kumar V (2020) Potential amelioration of waterborne iron toxicity in channel catfish (Ictalurus punctatus) through dietary supplementation of vitamin C. Ecotox. Environ. Safe. 205, 111337.

Yang J, Zhao H, Chan KM (2017) Toxic effects of polybrominated diphenyl ethers (BDE 47 and 99) and localization of BDE-99-induced cypla mRNA in zebrafish larvae. Toxicology Reports. 4, 614-624.

Yang J, Li Q, Li Y (2020a) Enhanced Biodegradation/Photodegradation of Organophosphorus Fire Retardant Using an Integrated Method of Modified Pharmacophore Model with Molecular Dynamics and Polarizable Continuum Model, Polymers 12, 1672. doi:10.3390/polym12081672

Yang L, Wang YH, Hao WY, Chang J, Pan Y, Li J, Wang H (2020b) Modeling pesticides toxicity to Sheepshead minnow using QSAR. Ecotox. Environ. Safe. 193, 110352. DOI:10.1016/j.ecoenv.2020.110352.

Yilmaz E (2020) Effect of dietary carob (Ceratonia siliqua) syrup on blood parameters, gene expression responses and ammonia resistance in tilapia (Oreochromis niloticus). Aquac. Res. 51, 1903-1912.

Young AS, Allen JG, Kim UJ, Seller S, Webster TF, Kannan K, Ceballos DM (2018) Phthalate and organophosphate plasticizers in nail polish: evaluation of labels and ingredients. Environ. Sci. Technol. 52, 12841-12850. https://doi.org/10.1021/acs.est.8b04495.

Yousefi M, Vatnikov YA, Kulikov EV, Ahmadifar E, Mirghaed AT, Hoseinifar SH, Doan HV, (2021) Effects of dietary Hibiscus sabdariffa supplementation on biochemical responses and inflammatory-related genes expression of rainbow 
trout, Oncorhynchus mykiss, to ammonia toxicity. Aquaculture 533, 736095.

Yousefi M, Vatnikov YA, Kulikov EV, Plushikov VG, Drukovsky SG, Hoseinifar SH, Doan HV (2020) The protective effects of dietary garlic on common carp (Cyprinus carpio) exposed to ambient ammonia toxicity. Aquaculture 526, 735400 .

Yu Y, Yu Z, Chen H, Han Y, Xiang M, Chen X, Ma R, Wang Z (2019) Tetrabromobisphenol A: Disposition, kinetics and toxicity in animals and humans. Environ. Pollut. 253, 909-917.

Zhang X, Zou W, Mu L, Chen Y, Ren C, Hu X, Zhou Q (2016) Rice ingestion is a major pathway for human exposure toorganophosphate flame retardants (OPFRs) in China. J. Hazard. Mater. 318, 686-693.

Zhang M, Li M, Wang R, Qian Y, (2018) Effects of acute ammonia toxicity on oxidative stress, immune response and apoptosis of juvenile yellow catfish Pelteobagrus fulvidraco and the mitigation of exogenous taurine. Fish Shellfish Immun. 79, 313-320.

Zhang L, Chen Y, Li C, Liu J, Ren H, Li L, Zheng X, Wang H, Han Z, (2019) RNA binding protein PUM2 promotes the stemness of breast cancer cells via competitively binding to neuropilin-1 (NRP-1) mRNA with miR-376a. Biomed. Pharmacother. 114, 108772.

Zhou LL, Püttmann W, (2019) Distributions of organophosphate flame retardants (OPFRs) in three dust size fractions from homes and building material markets. Environ. Pollut. 245, 343-352. 


\section{Tables and Figures Captions}

Table 1. Sensitivity coefficient of independent parameters of OPFRs molecular joint toxicity in 2D-QSAR model

Table 2. Average binding free energy and rank results of OPFRs molecules and JTR under the CFS

Fig. 1. Linear fitting diagrams and William's diagrams obtained within the application domain of the 2D-QSAR model

Fig. 2. Changes in binding free energies and OPFRs-JTR protein complexes in presence of 15 supplemental food, (A) high protein-rich foods, grains, and drinks, and (B) fresh fruits and vegetables

Fig. 3. Heat map of binding free energies of OPFRs molecules-JTR protein complexes with different CFS

Fig. 4. Annular histogram of binding affinity of OPFRs molecules (TCEP, TPHP, and TDCPP) simultaneously or in sequence binding with the neurotoxic receptor, reproductive toxic receptor, and endocrine disrupting toxic receptor

Fig. 5. Schematic diagram of the TS of nutrients from recommended CFS and OPFRs molecules docked with JTR (A) frontal view, and (B) rotation view

Fig. 6. Schematic diagram of absolute values of binding free energies of OPFRs and six metabolic kinases receptors in pregnant women with/without the recommended CFS 
Table 1. Sensitivity coefficient of independent parameters of OPFRs molecular joint

1051 toxicity in 2D-QSAR model

\begin{tabular}{|c|c|c|c|c|c|c|c|}
\hline \multirow{2}{*}{$\begin{array}{l}\text { Dependent } \\
\text { parameters }\end{array}$} & \multirow{2}{*}{$\begin{array}{l}\text { Independent } \\
\text { parameters }\end{array}$} & \multicolumn{6}{|c|}{ Sensitivity } \\
\hline & & $10 \%$ & $20 \%$ & $30 \%$ & $40 \%$ & $50 \%$ & Average \\
\hline \multirow{4}{*}{$\mathrm{T}_{\mathrm{a}}$} & $\mathrm{QYZ}_{\mathrm{Y}}$ & 0.01 & 3.94 & 3.26 & 2.81 & 2.51 & 2.51 \\
\hline & $E_{\text {LUMO }}$ & 133.20 & 10.86 & 6.26 & 4.54 & 3.71 & 31.71 \\
\hline & EG & 0.11 & 0.11 & 0.12 & 0.13 & 0.14 & 0.12 \\
\hline & $\begin{array}{c}\text { Raman-(C- } \\
\text { O)svf }\end{array}$ & -0.82 & -0.93 & -1.12 & -1.32 & -1.57 & -1.15 \\
\hline
\end{tabular}

1052

1053 Table 2. Average binding free energy and rank results of OPFRs molecules and JTR 1054 under the CFS

\begin{tabular}{ccccccccc}
\hline Level & $\mathrm{A}$ & $\mathrm{B}$ & $\mathrm{C}$ & $\mathrm{D}$ & $\mathrm{E}$ & $\mathrm{F}$ & $\mathrm{G}$ & $\mathrm{H}$ \\
\hline Presence & 52.05 & 63.86 & 47.60 & 54.06 & 56.69 & 52.91 & 56.29 & 54.12 \\
Absence & 56.19 & 44.37 & 60.64 & 54.18 & 51.55 & 55.33 & 51.95 & 54.11 \\
Rank & 5 & 1 & 2 & 7 & 3 & 6 & 4 & 8 \\
\hline
\end{tabular}



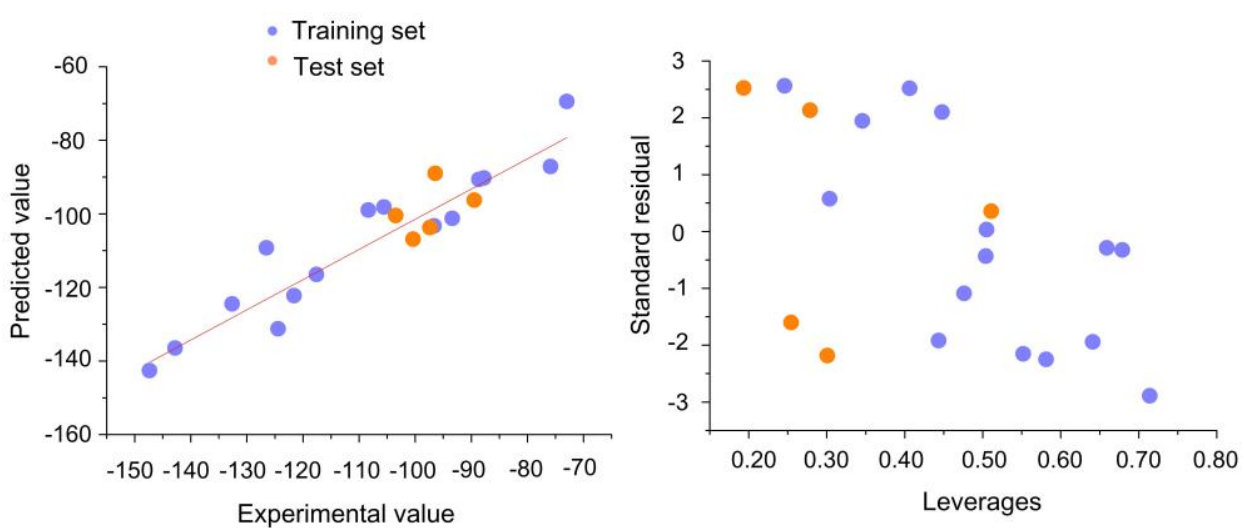

1056

Fig. 1. Linear fitting diagrams and William's diagrams obtained within the
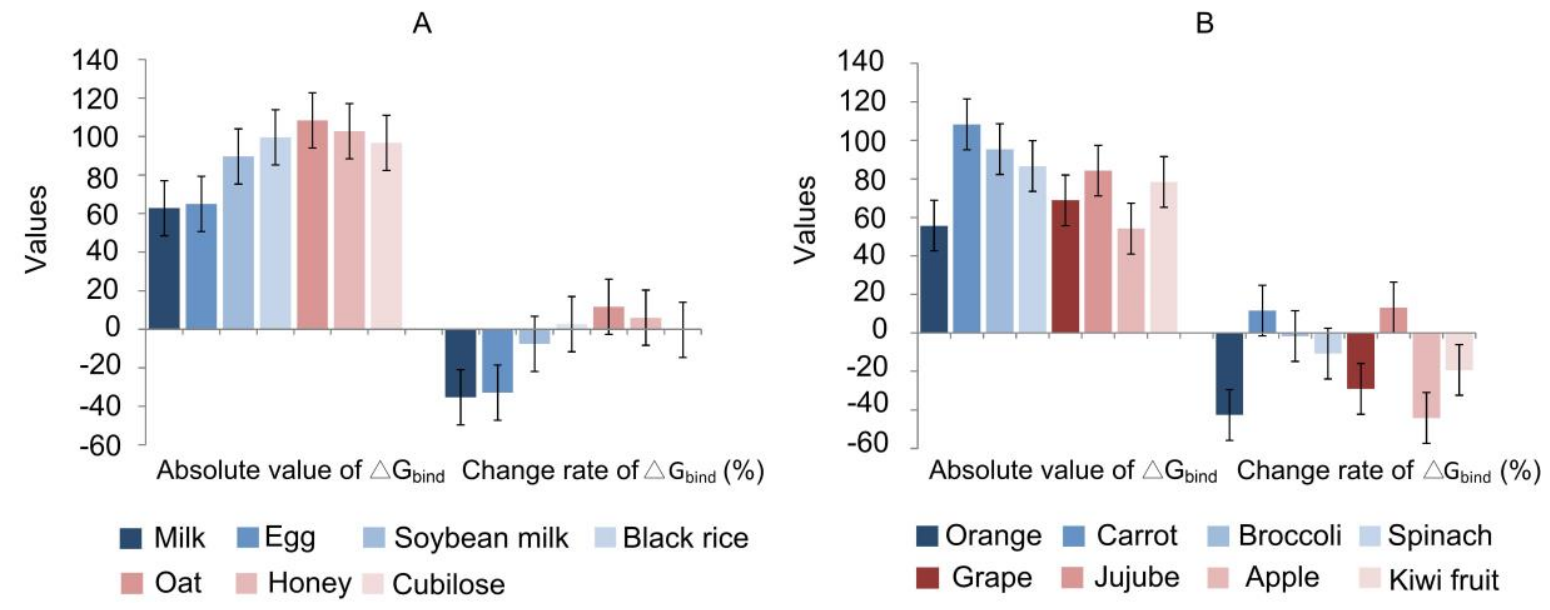

1060 Fig. 2. Changes in binding free energies and OPFRs-JTR protein complexes in 1061 presence of 15 supplemental food, (A) high protein-rich foods, grains, and drinks, and 1062 (B) fresh fruits and vegetables 


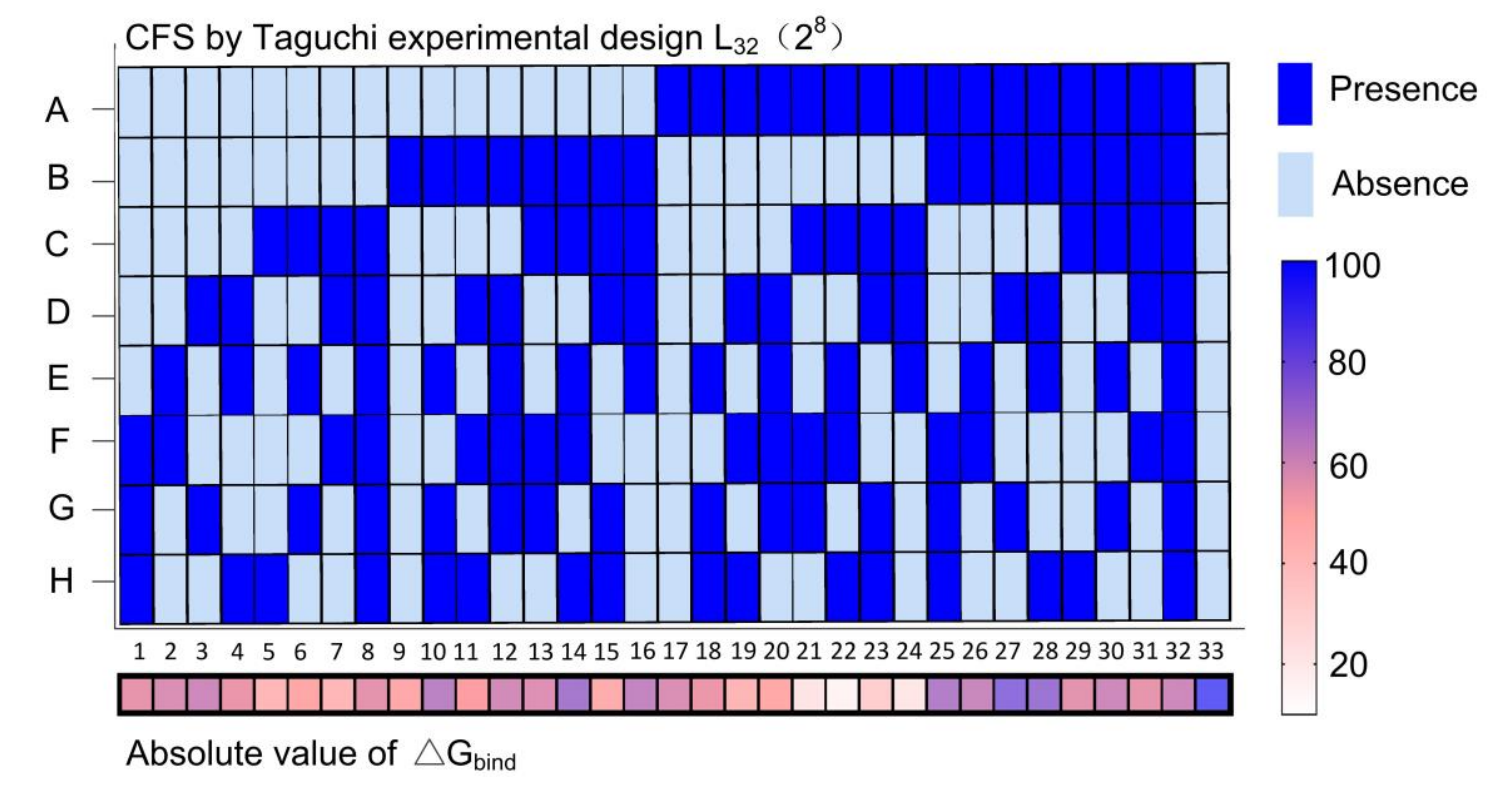

Fig. 3. Heat map of binding free energies of OPFRs molecules-JTR protein complexes with different CFS

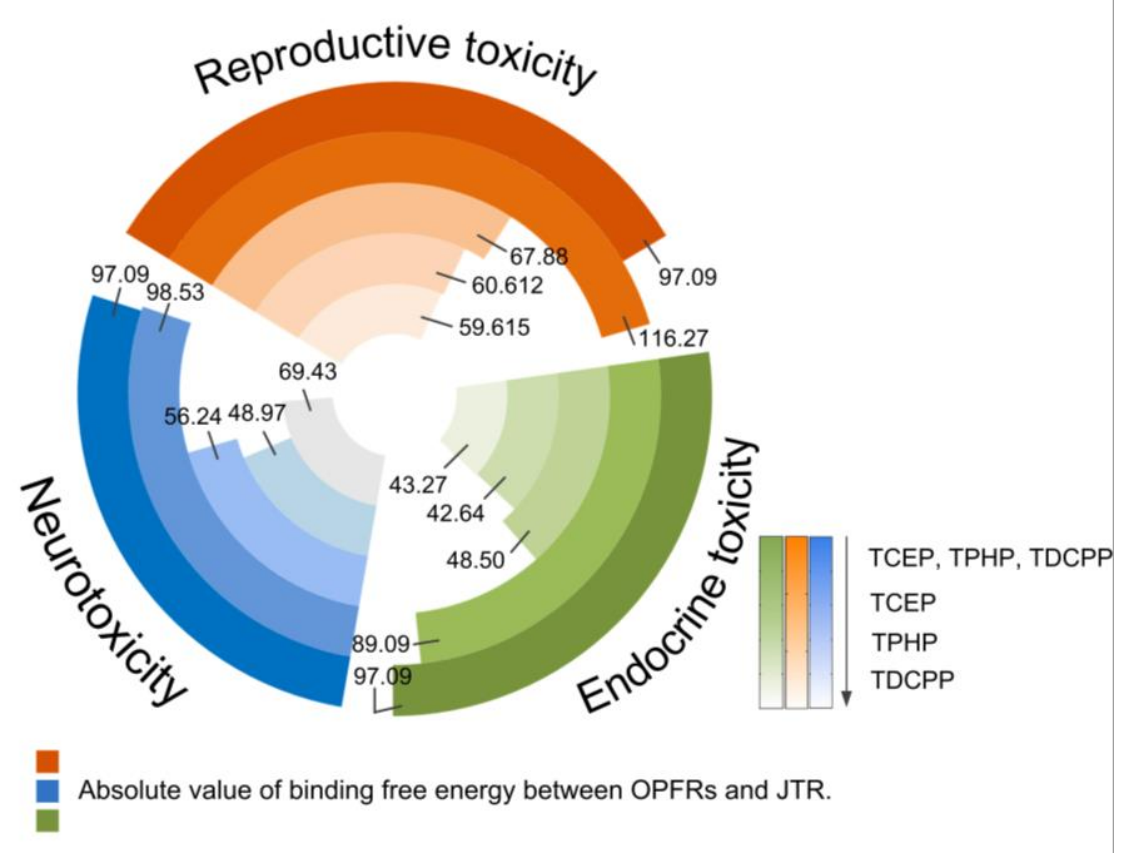

Fig. 4. Annular histogram of binding affinity of OPFRs molecules (TCEP, TPHP, and TDCPP) simultaneously or in sequence binding with the neurotoxic receptor, reproductive toxic receptor, and endocrine disrupting toxic receptor 


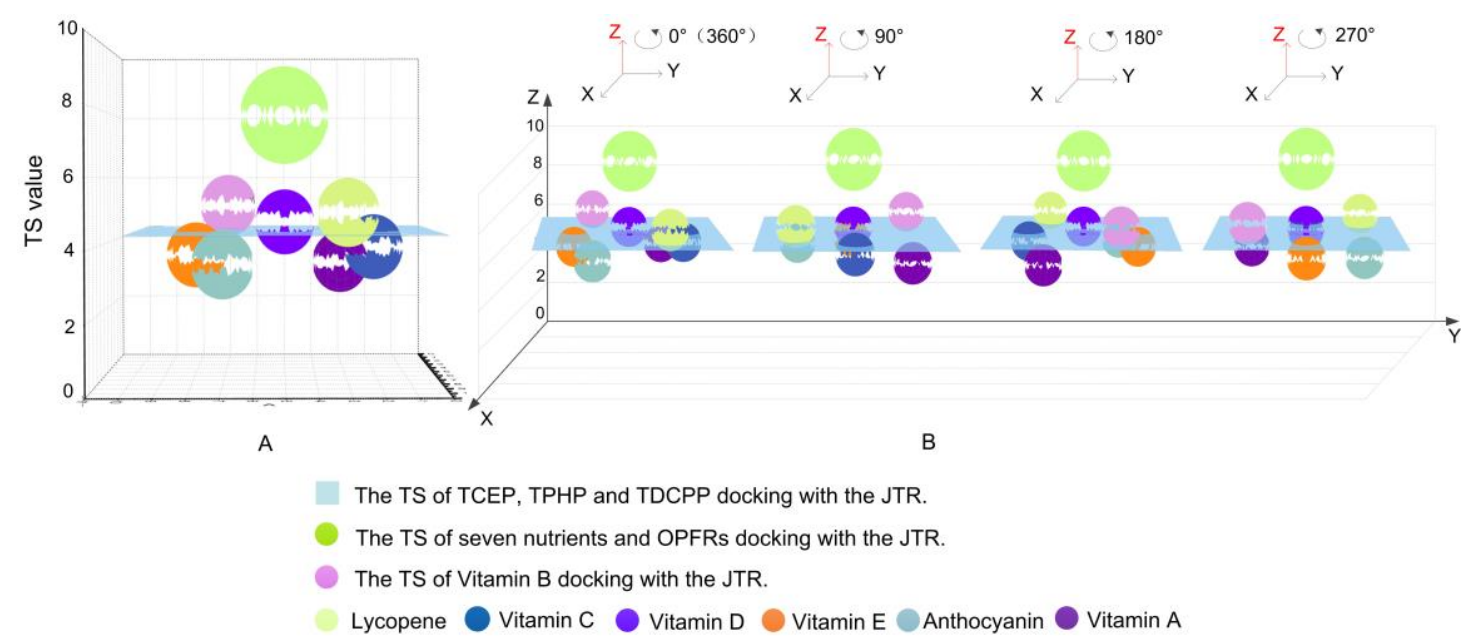

1074 Fig. 5. Schematic diagram of the TS of nutrients from recommended CFS and OPFRs

1075 molecules docked with JTR (A) frontal view, and (B) rotation view

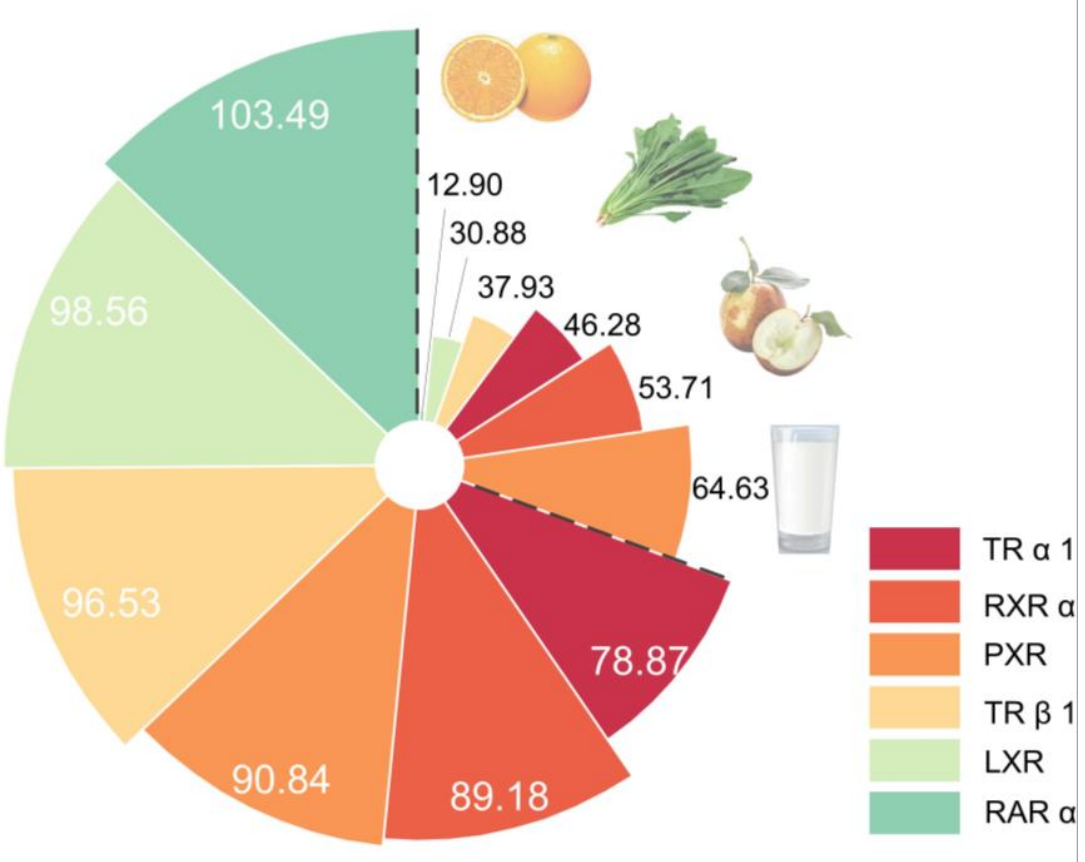

1078 Fig. 6. Schematic diagram of absolute values of binding free energies of OPFRs and six metabolic kinases receptors in pregnant women with/without the recommended 
Figures
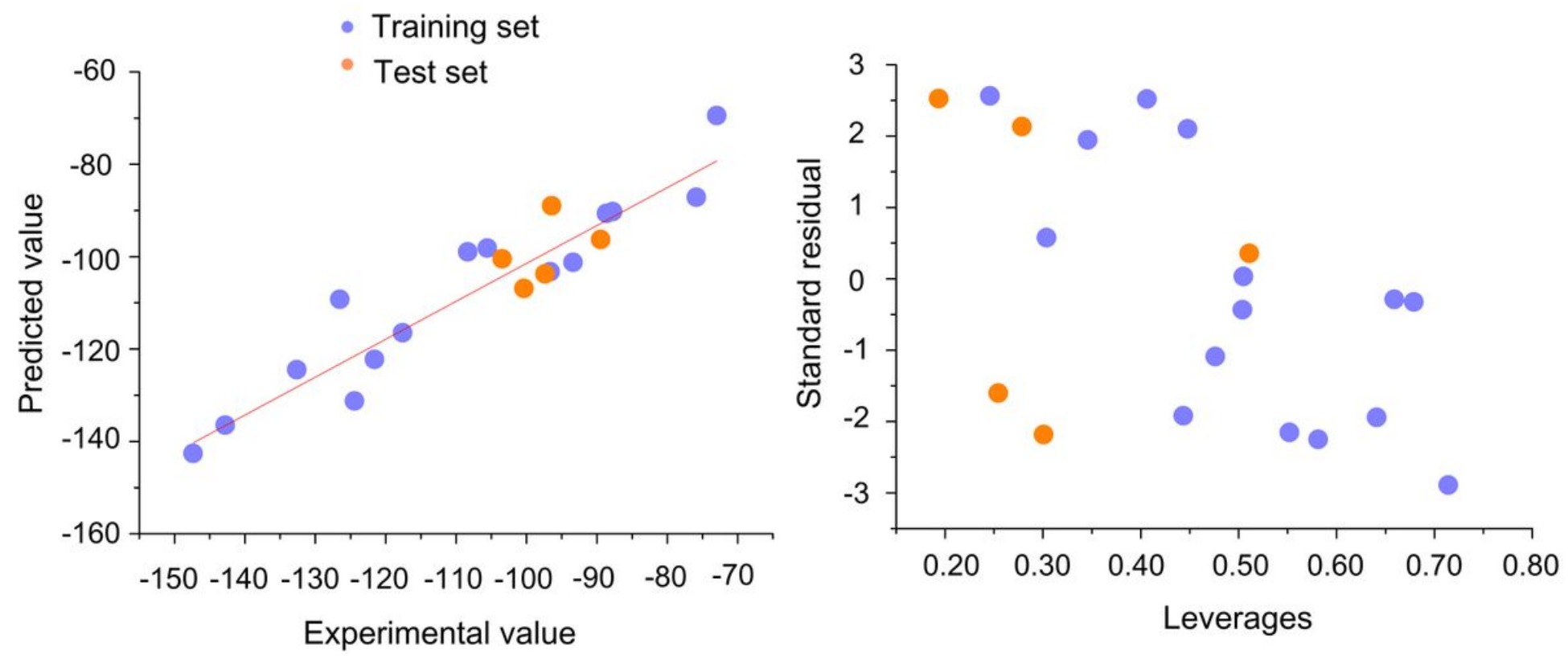

Figure 1

Linear fitting diagrams and William's diagrams obtained within the application domain of the 2D-QSAR model.

A

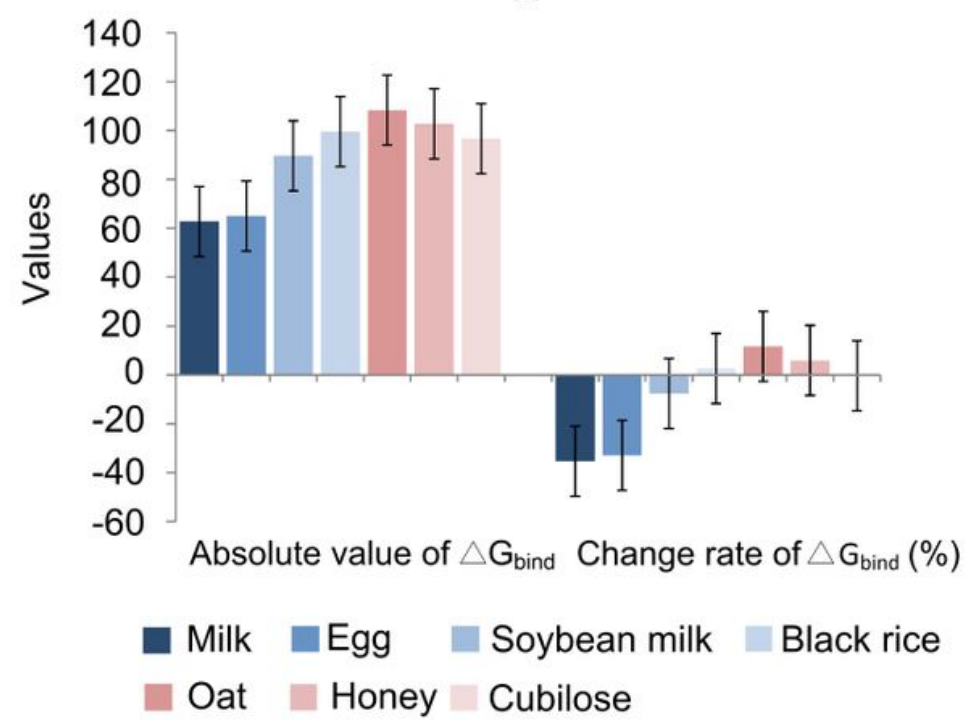

B

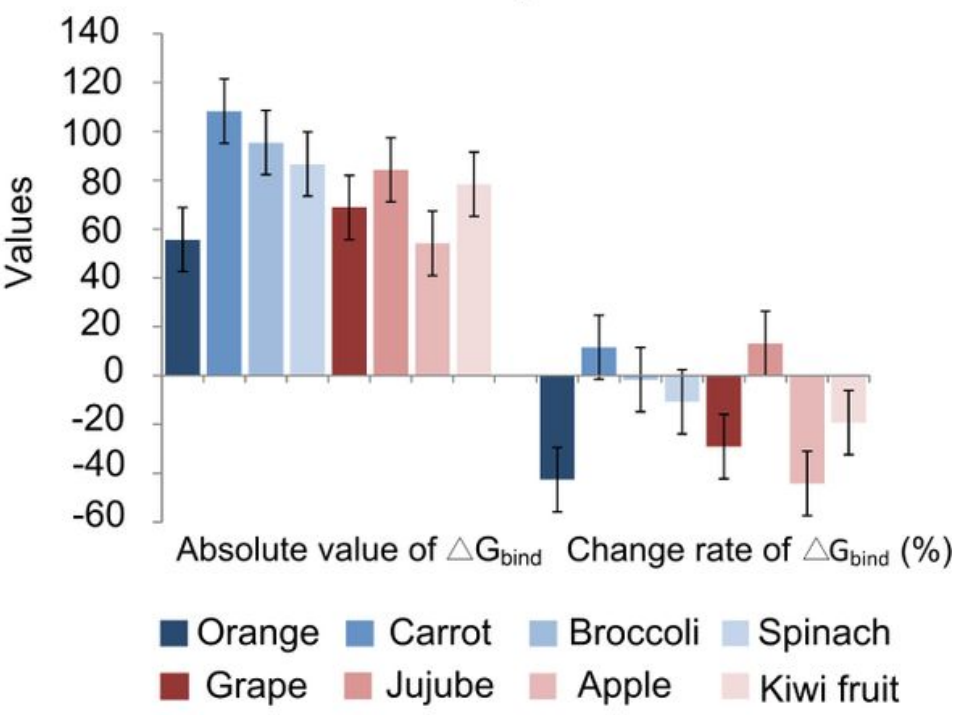

\section{Figure 2}

Changes in binding free energies and OPFRs-JTR protein complexes in presence of 15 supplemental food, (A) high protein-rich foods, grains, and drinks, and (B) fresh fruits and vegetables. 
CFS by Taguchi experimental design $\mathrm{L}_{32}\left(2^{8}\right)$

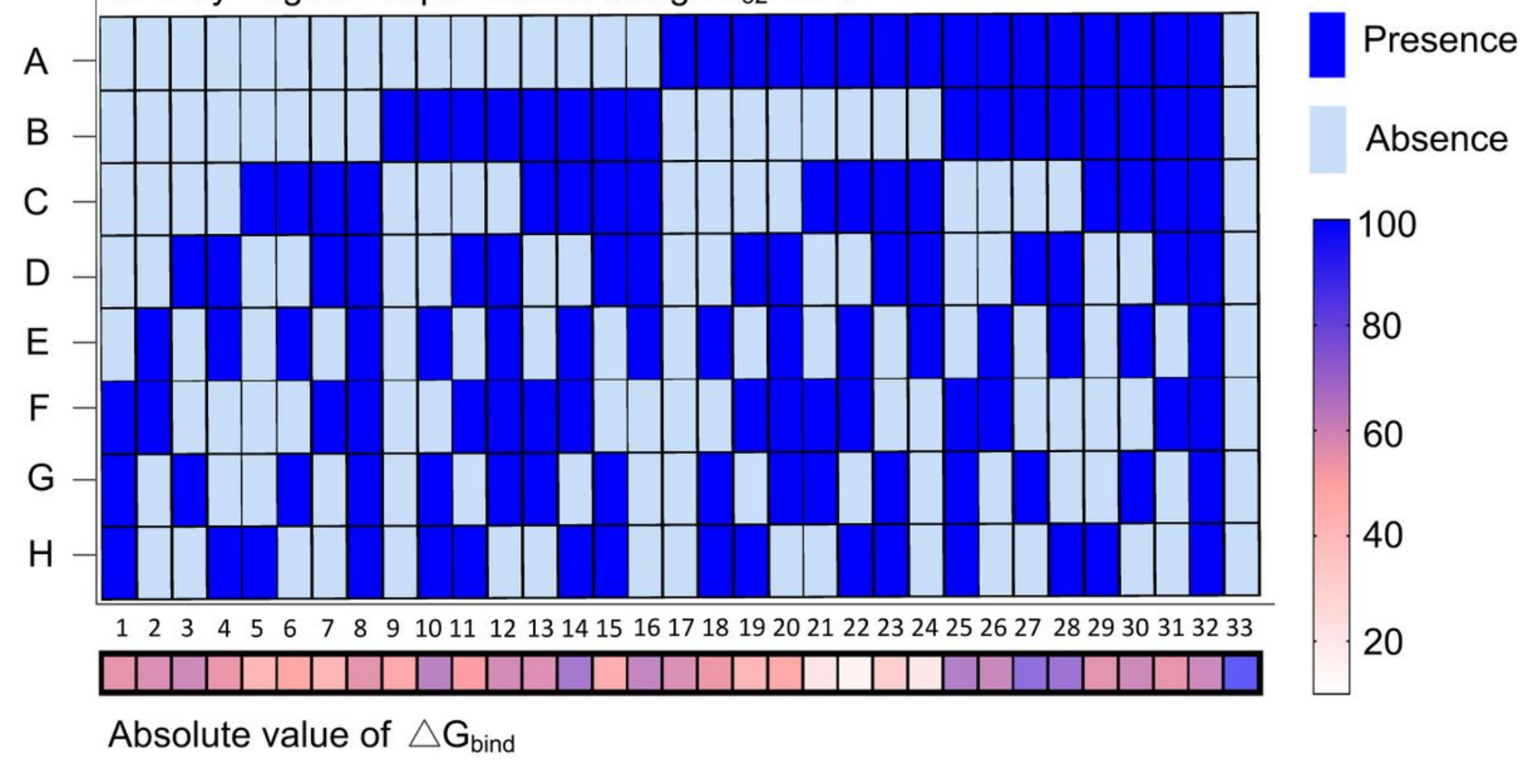

Figure 3

Heat map of binding free energies of OPFRs molecules-JTR protein complexes with different CFS. 


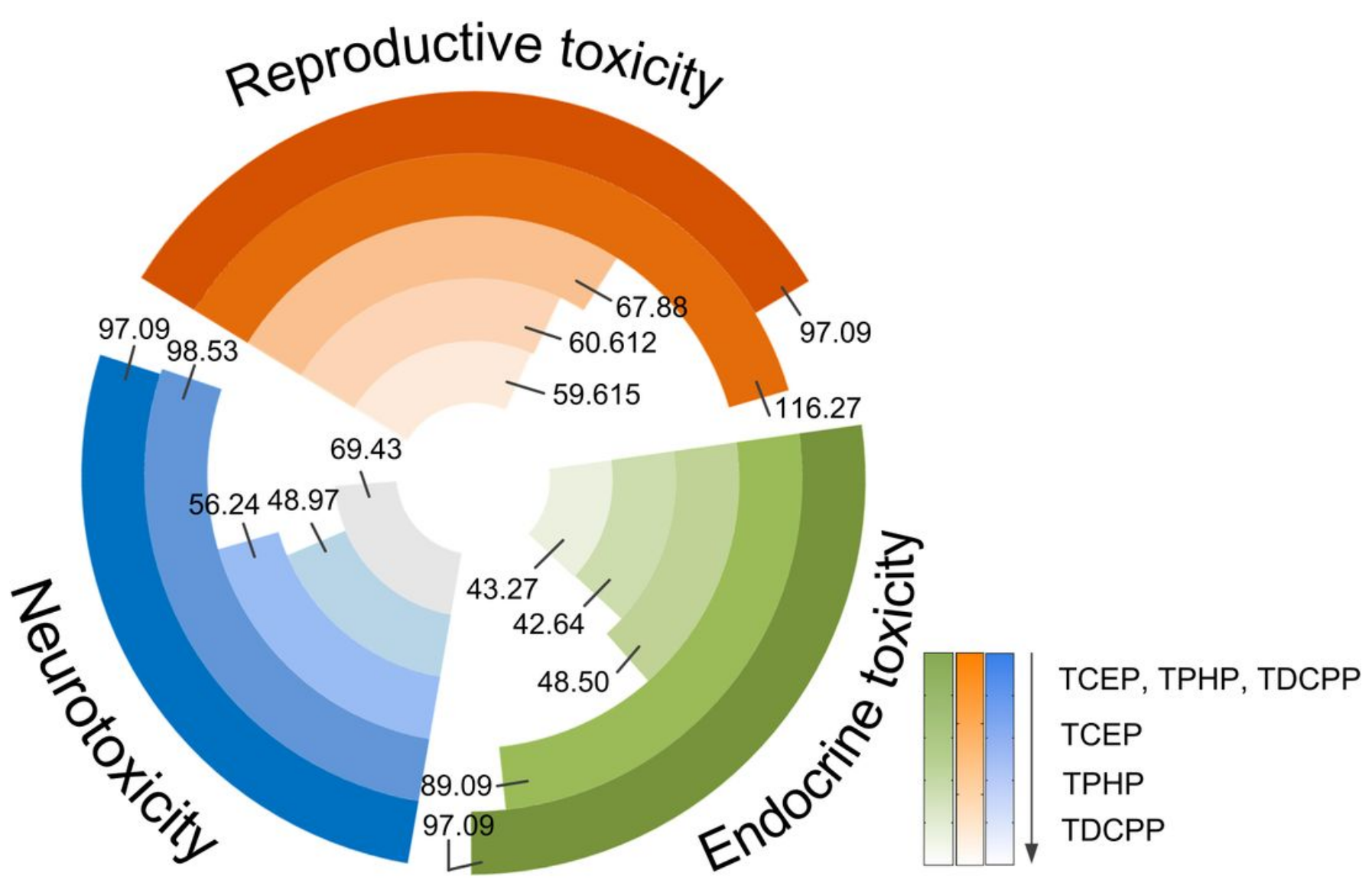

Figure 4

Annular histogram of binding affinity of OPFRs molecules (TCEP, TPHP, and TDCPP) simultaneously or in sequence binding with the neurotoxic receptor, reproductive toxic receptor, and endocrine disrupting toxic receptor. 


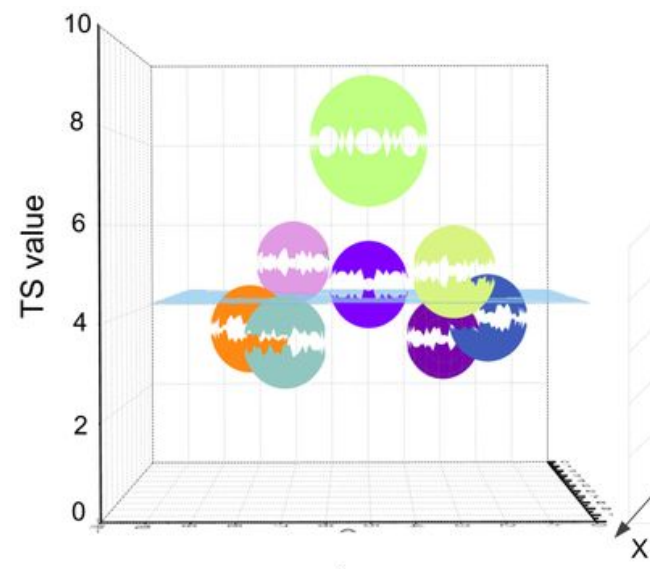

A

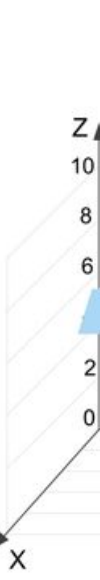

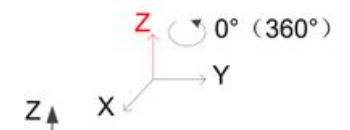

$Z \circlearrowleft 90^{\circ}$

$\mathrm{X} \longrightarrow \mathrm{Y}$

10
$\mathrm{X} \longrightarrow \mathrm{Y}$

$X \stackrel{Z}{Z}{ }_{Y}^{270^{\circ}}$

The TS of TCEP, TPHP and TDCPP docking with the JTR.

The TS of seven nutrients and OPFRs docking with the JTR.

The TS of Vitamin B docking with the JTR.

Lycopene Vitamin C Vitamin D Vitamin E Anthocyanin Vitamin A

\section{Figure 5}

Schematic diagram of the TS of nutrients from recommended CFS and OPFRs molecules docked with JTR (A) frontal view, and (B) rotation view. 


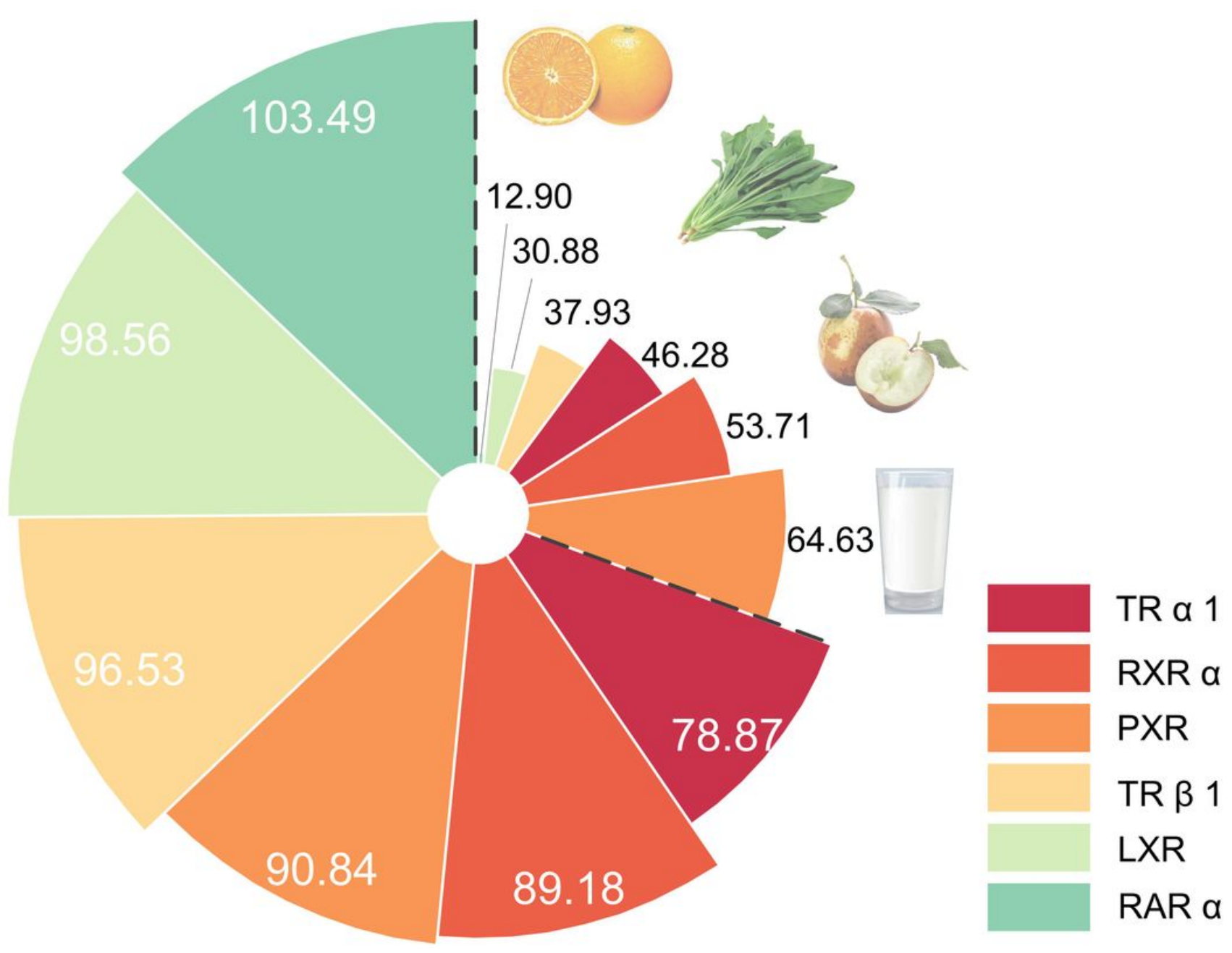

Figure 6

Schematic diagram of absolute values of binding free energies of OPFRs and six metabolic kinases receptors in pregnant women with/without the recommended CFS.

\section{Supplementary Files}

This is a list of supplementary files associated with this preprint. Click to download.

- Supplementaryfiles.docx 